\title{
ATTEMPTS TO IMPROVE THE YIELD OF BOVINE BLASTOCYSTS BY INCORPORATING INSULIN, SELENIUM AND TRANSFERRIN IN THE IN VITRO SYSTEM
}

by

\author{
CHLOE MELISSA BOWLES \\ BSc Agric., Natal
}

Submitted in partial fulfilment of the requirements

for the degree of

Master of Science in Agriculture

in the

Department of Animal Science and Poultry Science

Faculty of Agriculture

University of Natal

Pietermaritzburg

1996 


\section{PREFACE}

The experimental work described in this dissertation was carried out in the Department of Animal Science and Poultry Science, Faculty of Agriculture, University of Natal, Pietermaritzburg, from June 1995 to August 1996, under the supervision of Professor Arthur W. Lishman.

These studies represent original work by the author and have not otherwise been submitted in any form for any degree or diploma to any University. Where use has been made of the work of others it has been duly acknowledged in the text.

C.M. Bowles 
ii

\section{ACKNOWLEDGEMENTS}

I would like to express my sincere thanks and appreciation to the following institutions and persons for their invaluable contribution to the work presented in this thesis:

Prof. A.W. Lishman for his initiation of this study and constant help and guidance;

University of Natal (University Research Fund) and the FRD for financial assistance;

Dallas Shaw who gave immeasurable help and taught me all the techniques I needed;

Annari Faurie, Fiona Hartman and Kim Raja for helping in the laboratory and for always being friendly and willing to help;

Philip Jack (Taurus) for donation of materials;

The staff of Cato Ridge abattoir (especially Cliff Walker and Dr John Cullen) for endless friendly help with ovary collection;

Harvey Dicks for help in experimental design and statistical analysis;

All my friends and all of the masters students, technical staff and lectures for support and encouragement throughout my thesis;

Byron Stein for discerning support and good advice;

My parents for encouraging me and supporting me from the start. 


\section{CONTENTS}

PREFACE

ACKNOWLEDGEMENTS

ABSTRACT

GENERAL INTRODUCTION

\section{CHAPTER 1}

REVIEW OF LITERATURE

1.1 INTRODUCTION

1.2 IN VIVO REPRODUCTION

1.2.1 Structure and development of the oocyte

1.2.2 Spermatogenesis and fertilization

1.2.3 Structure and development of the embryo

1.3 IN VITRO REPRODUCTION

1.3.1 Oocyte recovery, selection and in vitro maturation

1.3.2 In vitro fertilization

1.3.3 In vitro culture

1.3.4 Insulin 22

1.3.5 Selenium 25

1.3.6 Transferrin 
CHAPTER 2

COMBINATIONS OF INSULIN, SELENIUM AND TRANSFERRIN THAT

MAXIMIZE MATURATION, FERTILIZATION AND CULTURE

2.1 INTRODUCTION

2.1.1 The selection of a bull for in vitro fertilization

2.1.2 Addition of insulin-transferrin-selenium (ITS) to maturation medium 30

2.1.3 The addition of insulin, selenium or transferrin individually or in combination to maturation, fertilization or culture medium

2.2.1 Oocyte recovery and selection

2.2.2 In vitro maturation procedure

2.2.3 Maturation controls

2.2.4 Assessment of sperm motility and morphology

2.2.5 In vitro fertilization procedure

2.2.6 Fertilization controls

2.2.7 In vitro culture procedure

2.2.8 Experimental design and statistical analysis

2.3.1 Bull selection

2.3.2 Addition of ITS to maturation medium

2.3.3 Insulin, selenium and transferrin in the maturation, fertilization and culture medium 
2.4 DISCUSSION

2.4.1 Bull selection $\quad 45$

2.4.2 ITS added to maturation medium 45

2.4.3 Insulin, selenium or transferrin added individually or in combinations to maturation, fertilization or culture media 46

2.5 FUTURE WORK

$\begin{array}{ll}\text { IMPLICATIONS } & 51\end{array}$

REFERENCES

$\begin{array}{ll}\text { APPENDIX } 1 & 62\end{array}$

$\begin{array}{ll}\text { APPENDIX 2 } & 66\end{array}$ 


\begin{abstract}
To produce an embryo via in vitro maturation, in vitro fertilization and in vitro culture methods it is vital to obtain consistent results and at the same time a large number of blastocysts from the immature oocytes collected, especially when only a small pool of these oocytes are available.

The aim of the present investigation was to improve maturation rates, fertilization rates and blastocyst production rates by adding insulin $(10 \mu \mathrm{g} / \mathrm{ml})$, selenium $(10 \mathrm{ng} / \mathrm{ml})$ or transferrin $(10 \mu \mathrm{g} / \mathrm{ml})$ to the media. These were added individually or in different combinations and a complete randomised block design was set up to account for block and day effects. It was hypothesised that each treatment would improve maturation and fertilization rates and blastocyst production rates.
\end{abstract}

It was found that of the treatments added to the maturation medium, Selenium at $10 \mathrm{ng} / \mathrm{ml}$ improved maturation percentages $(80.4 \%$ vs $61.8 \%$ ) and also increased fertilization percentages $(68.0 \%$ vs $58.4 \%$ ) and the number of blastocysts produced ( $24.6 \%$ vs $11.5 \%$ ). None of the treatments had a beneficial effect on fertilization rates or on blastocyst production rates when added to the fertilization medium. The treatments added to the culture medium showed that Transferrin at $10 \mu \mathrm{g} / \mathrm{ml}$ or Transferrin in combination with Insulin and Selenium increased the percentage of blastocysts produced by in vitro culture methods (35.3\% and $31.5 \%$ vs $18.7 \%$ ). The addition of Transferrin also increased the percentage of blastocysts that hatched (21.9\% vs $14.2 \%)$ showing an improvement in the viability of the blastocysts produced.

It is recommended that the maturation medium should include Selenium at $10 \mathrm{ng} / \mathrm{ml}$. The fertilization process should have none of the investigated substances added to it and the culture medium should include Transferrin at $10 \mu \mathrm{g} / \mathrm{ml}$. This combination should optimize the number of viable blastocysts that are produced in a bovine in vitro system. 


\section{GENERAL INTRODUCTION}

The world of animal production has undergone great technological changes in the past 40 years. From a handful of laboratories conducting research on in vitro maturation (IVM) and fertilization (IVF) of cattle oocytes seven years ago, the number currently active in producing cattle embryos for research and other purposes must now be well in excess of 100 (Gordon, 1994). The earliest studies exclusively devoted to bovine oocytes recovered from slaughterhouse ovaries were in 1968 when it was reported that nuclear maturation occurred after a period of 24 hours in culture (Gordon, 1994). The first genuine success in the fertilization in vitro of an artificially matured bovine oocyte is that recorded by Iritani and Niwa (1977) in Japan. One of the first pregnancies produced by totally in vitro procedures (IVM, IVF and in vitro culture (IVC) of the early embryo) was reported from Dublin by Lu et al. (1987) and resulted in the birth of twins. In 1994 the first IVF calf was born in Africa.

Research in laboratory embryo production has focused mainly on cattle as the technology is much further developed in this species than among other farm animals. Cattle embryos can now be produced in a semi-consistent, semi-predictable way and they can survive freeze-thawing and after transfer to recipient females they can give rise to normal pregnancies. What can be achieved in cattle could be equally possible with appropriate modifications, in most of the other farm species and also wildlife species.

There is considerable scope for much further research to improve the technology of cattle embryo production. In most cattle IVF laboratories the production of blastocysts plateaus at $20-30 \%$ of the inseminated oocytes, even under numerous variations on the basic technique. The fact that the majority of oocytes after fertilization do not develop into usable embryos is a measure of the ground still to be covered and one of the reasons why researchers need to investigate the composition of culture media. It is logical to expect that in order to improve in vitro systems one might need to understand what happens in vivo. 
During the last few years increasing attention has been paid to the influence of selenium (Se) on the reproductive performance of cattle and other animals. The beneficial effects of selenium in livestock have generated much interest especially since Se-deficient areas have been identified. A Se deficiency can occur where cattle are fed on pasture, crops or grain from crops grown on soil containing less than $0.5 \mathrm{mg}$ Se per $\mathrm{kg}$ dry matter (DM) and feedstuffs containing less than $0.05 \mathrm{mg}$ Se per $\mathrm{kg}$ DM (McClure, 1994). Studies have demonstrated the effectiveness of supplemental Se in increasing various aspects of reproductive efficiency in female ruminants (Buchanan-Smith et al., 1969; Segerson et al., 1977). Buchanan-Smith et al (1969) reported that Se increased the conception rate in ewes and Segerson and Ganapathy (1981) suggest that the improved birth rate in Se treated ewes and beef cattle is due to a decrease in early embryonic mortality and to an increased fertility of ova. Segerson et al. (1977) showed that fertilization of beef cattle ova was $100 \%$ in those females receiving supplemental Se on an adequate plane of nutrition.

Brown and Burk (1973) demonstrated that the rat uterus incorporates selenium, suggesting that selenium is involved in rat uterine function. Selenium has been implicated as necessary for proper functioning of various reproductive characteristics in the mammalian female (Julien et al., 1976). According to Buck et al. (1980a) suboptimal selenium in the diet might lead to Se deficiency in the ovary and uterus and lead to dysfunction of the reproductive processes of the female and be manifested as reduced fertility. The role of selenium in ovarian function has not been established. However, Buck et al. (1980b) found Se in ovarian tissue from the goat and showed that Se was accumulated preferentially by the placentome, ovary, pituitary and adrenal glands which suggests a need for Se in these body tissues. Harrison et al. (1984a) found selenium activity in the ovarian tissue of cows and found $\mathrm{Se}$ in the follicular fluid of follicles.

Selenium functions as a component of glutathione peroxidase that acts to destroy peroxides that can attack and oxidise the lipids in the cell membrane and thereby alter the integrity of the cell membrane (Segerson and Ganapathy, 1981). Harrison et al. (1984b) suggest that as Se protects cells from oxidative damage, then Se may play a role in protecting ova prior to ovulation and therefore have an effect on subsequent fertilization. The effects of selenium upon fertilization warrants further investigation and should also be studied further in view of its antiperoxidative role against oxidative damage of cells and tissues. 


\section{CHAPTER 1}

\section{REVIEW OF LITERATURE}

\subsection{INTRODUCTION}

Only a few years ago, it would have appeared unlikely that viable cattle embryos could be produced from oocytes collected at the local abattoir. Given the present inadequate understanding of the mechanisms regulating oocyte maturation, fertilization and embryo development both in vivo and in vitro, it is remarkable that viable embryos can be produced from the culture of immature oocytes in vitro that undergo in vitro maturation (IVM) and in vitro fertilization (IVF) followed by in vitro culture (IVC). The percentage of oocytes reaching the blastocyst stage in a completely in vitro system is quite low (20\%), but with the development of in vitro techniques, the laboratory production of farm animal embryos has excellent potential, both for research and for practical applications on the farm.

Extremely careful attention to detail is required at all stages of bovine embryo production if consistently high yields are to be achieved. The efficiency of the technique (blastocyst yield) is not quite satisfactory due to inadequate information about the requirements of the bovine embryos for development in culture and of oocytes for achieving normal maturation. The proportion of ova developing to blastocysts are markedly affected by the combination of culture mediums used. Hawk and Wall (1994b) found that conditions under which bovine oocytes are matured in vitro can affect the proportion of oocytes that subsequently develop to morula and blastocysts during in vitro culture.

According to Sanbuissho and Threlfall (1990) in vitro maturation of the bovine oocyte can be successful if specific requirements in the culture environment are met and the maturation processes of the oocyte have to be satisfied for fertilization of the oocytes to occur with full developmental capacity. The maturation of the oocyte is a complex phenomenon involving both the nucleus and the cytoplasm (Tornesi et al., 1995). Oocytes aspirated from bovine ovaries are being used throughout the world for in vitro maturation and fertilization to provide embryos for experimentation or for transfer to recipient females. The media used for in vitro maturation of oocytes and for culture of embryos vary between 
laboratories and thus the proportion of oocytes that develop to morula or blastocysts vary considerably. Hawk and Wall (1994b) suggest that developing a system which best mimics the conditions that are found in vivo might increase the proportion of oocytes and cleaved zygotes that develop to expanded blastocysts. Failure to achieve high rates of success of culture oocytes and embryos may reflect the absence in culture of factors normally present in the in vivo environment of the oocytes or embryos (Rexroad and Powell, 1988).

The development of bovine IVM and IVF embryos up to the blastocyst stage is now possible under a wide range of culture conditions, but there are big differences in the quality of the blastocysts with regard to morphology, cell numbers and viability after cryopreservation (freezing) compared to normally produced in vivo embryos (Shamsuddin et al, 1994). According to Shamsuddin et al (1994) blastocysts that are developed in vitro have poor viability and show poor cellular organization, with a blastocoel surrounded by less organised trophoblastic cells and an indistinct inner cell mass.

Culture media for in vitro maturation, in vitro fertilization and early embryonic development in cattle are usually supplemented with a variety of serum preparations from animals such as foetal calf serum (FCS) and bovine serum albumin (BSA), which are most common. Serum contains many kinds of components such as serum proteins, amino acids, carbohydrates, trace elements, hormones, growth factors, cell attachment and spreading factors and some as yet undefined, factors (Takagi et al, 1991). Kobayashi et al. (1994) accept that hormones (for example oestrogens, progesterone, luteinizing hormone (LH) and follicle stimulating hormone (FSH)) play a major role in stimulating the resumption of meiosis in mammalian oocytes and in the expansion of the cumulus oophorus in vivo, but think it is possible that other hormonal factors also influence meiotic maturation of mammalian oocytes during the preovulatory period. Sanbuissho and Threlfall (1990) suggest that FCS contains some undefined growth promoting components that are absent from the serum of adult animals and/or that FCS lacks components (hormones and immunoglobulins) present in the adult serum that retard the in vitro development of the cells. Shamsuddin et al.'s (1994) explanation for the poor development of in vitro produced embryos is that media supplemented sera are deficient in substances necessary for building a proper cytoskeleton and cellular differentiation of the embryo. Even though serum is a physiological vehicle for transportation of nutrients, and contains insulin, selenium and transferrin and many other essential elements and growth promoters, the concentrations of these substances in the culture medium 
are only $5 \%$ to $20 \%$ of the physiological level (most laboratories supplement embryo culture medium with $5 \%$ to $20 \%$ serum).

Despite the successful in vitro culture of preimplantation embryos from a number of mammalian species, such embryos are at a developmental disadvantage when compared to their in vivo counterparts, perhaps because specific growth factors must be present in the culture media to accomplish optimal development (Kane et al., 1992). This can be overcome, to some extent, by adding growth factors or flushings from the reproductive tract, such as co-culturing with oviductal or uterine cells. The oviduct is where the mammalian egg is normally fertilized and where the first few cell divisions of the embryo take place. Sutton et al. (1984) think specific proteins in the oviductal fluid are needed to facilitate fertilization in cattle and that identification of these proteins in oviductal fluid from oestrous or pregnant animals could reveal components which are important for fertilization and early embryonic development. Heyner et al. (1993) showed that these proteins and/or growth factors act along a paracrine pathway by binding to specific receptors on embryonic cells. The embryo itself produces some autocrine growth factors and optimal development is obtained by support from its physiological environment. The involvement of growth factors is important in the processes of cellular proliferation, differentiation and morphogenesis in mammalian early development (Heyner et al., 1993).

Early embryonic development in vitro is related to, or can be affected by, a wide variety of intrinsic and extrinsic factors such as inorganic ions, buffers, gas composition, amino acids, growth factors, vitamins and macromolecules (Rieger, 1992). Multiple factors may prove critical to the outcome of IVM/IVF/IVC. The isolation and identification of any single influential factor is difficult, although much research has been done on the various methods to improve the culture of oocytes and thereby the number of embryo's that are produced. Evidence is accumulating that factors promoting the growth of various types of tissue and cells may also control the growth of early mammalian embryos (Zhang et al, 1994). Insulin is essential for follicle culture. Lack of insulin resulted in follicular degeneration and addition of selenium, as an acceptor of free radicals generated during cell metabolism, improved culture conditions (Roy and Greenwald, 1989). Also, serum included in media for IVM has been shown to improve oocyte maturation and subsequent embryo development. Serum contains many components, including hormones, growth factors and binding proteins such as transferrin (Tornesi et al., 1995) 
In somatic cell culture insulin, selenium and transferrin (ITS) either individually or in different combinations were found to be essential for many cell lines when serum free medium was used (Jewgenow and Pitra, 1993). Shamsuddin etal. (1994) added ITS to bovine co-culture medium and IVM/IVF embryos developed up to the blastocyst stage in a serum free medium, although the effect of ITS was not shown separately. It seems rational to study the effects of ITS supplementation in searching for improved culture systems for bovine embryo development. There are several physiological effects of insulin, selenium and transferrin that might have improved the development and viability of the embryos (Shamsuddin et al, 1994). Further research is needed to improve the culture system, not only to increase the rate of blastocyst development, but also to qualify the blastocyst with survivability comparable to that of in vivo produced embryos.

\subsection{IN VIVO REPRODUCTION}

Before any effects of insulin, selenium or transferrin on oocyte or embryo development can be understood, knowledge of the structure and development of the oocyte and of the embryo in vivo is important.

\subsubsection{Structure and development of the oocyte}

The mammalian ovary contains vast numbers of primordial follicles which contain oocytes arrested in the diplotene stage of the first meiotic prophase, with the chromosomes still enclosed by a nuclear membrane within a nucleus generally known as the germinal vesicle (Johnson and Everitt, 1980). The diplotene stage is completed shortly after birth when oocytes then enter a prolonged 'resting phase', which is terminated shortly before ovulation at puberty, when primordial follicles are recruited into growing follicles (Austin and Short, 1982).

According to Austin and Short (1982) the oocyte and its granulosa cells contain cytoplasmic organelles such as mitochondria, Golgi vesicles, endoplasmic reticulum (smooth type) and ribosomes. The latter contain an array of enzymes which are involved in important metabolic and synthetic activities, where 
chromosomes actively synthesise large amounts of ribonucleic acid (RNA). This loads the oocyte cytoplasm with materials that are essential for later stages of ovum maturation. The oocyte shows a high degree of metabolic and synthesis activity (Austin and Short, 1982). The surrounding granulosa cells divide to become several layers thick and secrete a glycoprotein material that forms an acellular layer, the zona pellucida (Johnson and Everitt, 1980).

A fluid filled space occurs between the cell surface and the zona pellucida, called the perivitelline space and the oocytes mass of spherical cytoplasm (70 - $120 \mu \mathrm{m}$ in diameter) is bound by a plasma membrane inside of this space and the zona pellucida (Austin and Short, 1982). The plasma membrane consists of phospholipids arranged in two layers. Protein molecules are held in the membrane, their fat soluble portions lying in a hydroscopic zone and their electrostatically charged water soluble extremities extending either into the cell cytoplasm or the external medium (Austin and Short, 1982). Some proteins are not integral with the membrane, but are simply adsorbed onto the surface and a single protein traversing the membrane may link up with the cytoskeleton of the cell and serve to transmit influences from the external environment to the cytoplasm. If the protein has a water soluble core it could provide a channel for the passage of ions into and out of the cell (Austin and Short, 1982).

The zona pellucida consists of mucopolysaccharide and trypsin-digestible material and forms an impervious jelly-like coat around the oocyte and contact with the oocyte is maintained via cytoplasmic processes (microvilli) that penetrate the zona pellucida and form gap junctions at the oocyte surface. There are also micro tubular connections between the cumulus oophorus (dense mass of granulosa cells surrounding oocyte) and the zona pellucida (Johnson and Everitt, 1980). Mammalian oocytes are dependent on adequate follicle cell support and the presence of an extensive and direct junctional communication between the follicle cells and the oocyte. This system facilitates the production of nutrients and hormones and their transport into the oocyte and generates signals that control and regulate oocyte metabolism as well as nuclear and cytoplasmic maturation (Austin and Short, 1982).

The cumulus cell surrounded oocyte is suspended in follicular fluid which resembles blood serum in composition and is probably derived from the capillaries, which surround a follicle, with slight modification by the follicle cells (Johnson and Everitt, 1980). It is comprised partly of mucopolysaccarides secreted by the granulosa cells and oestrogens, progestagens and androgens, as 
well as other intra follicular molecules such as growth factors, proteinases, plasmin, alkaline phosphatase, acid phosphatase, lactate dehydrogenase, aspartate amino transferase, alanine amino transferase and hyaluronoglucosidase (Johnson and Everitt, 1980). The steroid hormones found in follicular fluid act on cumulus cells rather than directly on the oocyte and act on the oocyte via metabolic intermediates (Austin and Short, 1982).

In the normal course of events one primary oocyte is selected to mature and ovulate. Changes occur in the Graafian follicle (FSH level elevated, followed by LH peak and increase in oestrogen level), and dramatic changes occur in the oocyte as the nuclear membrane surrounding the dictyate chromosomes breaks down (germinal vesicle breakdown). The arrested meiotic prophase is ended and then the chromosomes progress through the remainder of the first meiotic division culminating in an extraordinary cell division in which half of the chromosomes and almost all the cytoplasm, goes to one cell, the secondary oocyte and the remaining chromosomes are discarded in a small bag of cytoplasm, the first polar body (Austin and Short, 1982). The chromatids within the secondary oocyte separate at their centromeres and lie on the second metaphase spindle (metaphase II plate) and then meiosis arrests again until the mature egg is fertilized (Johnson and Everitt, 1980).

Meiotic maturation is accompanied by cytoplasmic maturation in which changes occur in the cytoplasmic organisation of the oocyte. The Golgi apparatus of the oocyte synthesize lysosomal-like granules, which migrate towards the surface of the oocyte (cortical granules) and protein synthetic activity continues (new and distinctive proteins). This prepares the oocyte for fertilization (Johnson and Everitt, 1980). When primary oocytes are removed and placed in culture in vitro they will spontaneously undergo meiotic nuclear maturation, but not cytoplasmic maturation. Normal cytoplasmic maturation of the oocyte is achieved only if the oocyte is retained within the follicle or if the conditions in culture in vitro are the same as those found in vivo (Johnson and Everitt, 1980). 


\subsubsection{Spermatogenesis and fertilization}

Spermatogenesis is the formation of mature sperm within the reproductive tract. The end point is an immotile spermatozoon in the epididymis. In mammals, fertilization takes place in a protected and well controlled environment within the oviduct.

The critical changes that confer normal fertilizability are reflected in a developing capacity of the oocyte to take part in four events: i) sperm-head engulfment, ii) exocytosis of cortical granules, iii) dispersal of the sperm nuclear envelope and iv) decondensation of the sperm chromatin (Mastroianni and Biggers, 1981). For the spermatozoa two events need to occur: i) they must mature while passing through the epididymis and ii) the spermatozoa need to capacitate (additional maturation) within the female genital tract before they are able to fertilize oocytes (Mastroianni and Biggers, 1981).

Epididymal maturation includes various morphological, physiological and biochemical changes in the sperm components. The one recognizable change is the development of the spermatozoon's potential to move (spermatozoon must sustain progressive motility to pass through the coats around the oocyte) (Mastroianni and Biggers, 1981). It is well established that the sperm plasma membrane has the property of absorbing a variety of substances from its environment, some of which come from the seminiferous tubule, some from the epididymis and some from the vas deferens (Mastroianni and Biggers, 1981). The removal or alteration of these substances from the sperm plasma membrane constitutes a part of capacitation and occurs in the female tract and capacitation enables the acrosome reaction to take place (Mastroianni and Biggers, 1981). The acrosome must 'react' or breakdown and release its enzymes as a spermatazoon with an intact acrosome cannot penetrate an oocyte (Austin and Short, 1982). The lytic action of the enzymes aids the passage of spermatozoon through the oocyte investments. The most important enzymes being hyaluronidase and a powerful trypsin-like enzyme called acrosin. Both play important roles in sperm penetration of the oocytes coats (Austin and Short, 1982).

Spermatozoa attach to the zona pellucida before they penetrate it and the species specificity of sperm attachment to the zona surface is very distinct (Mastroianni and Biggers, 1981). Penetration occurs with strong motility of the spermatozoon and enzymatic (acrosin) dissolution of the zona pellucida and 
once the sperm has successfully penetrated the cumulus cell investment and entered the zona pellucida, fusion with the vitelline membrane of the oocyte occurs (Johnson and Everitt, 1980). Fusion evokes exocytosis of cortical granules in the oocyte and these effect changes in the zona pellucida, which are responsible for the block to polyspermy (multiple sperm penetration), where the entry of more than one sperm leads to abnormal embryogenesis and early death (Johnson and Everitt, 1980). Fusion also stimulates the metaphase spindle of the secondary oocyte to complete its division, one half of the chromatin then being extruded within the second polar body and the remaining chromosomes reaggregate and decondense to form a female pronucleus and decondensation of the sperm nucleus occurs to form a male pronucleus. Fusion of the male and female pronuclei completes the fertilization process (Austin and Short, 1982).

\subsubsection{Structure and development of the embryo}

Embryonic development within the female occurs in the oviduct and the uterus. After fertilization in the oviduct the egg is transported down the oviduct and into the uterus. The journey takes two to four days and the oviduct should not be traversed too rapidly (Austin and Short, 1987). All mammalian embryos are dependent on a continuing supply of energy from the maternal environment (Austin and Short, 1987). Ribosomal and transfer RNA are produced as early as the 2-cell stage and early RNA synthesis is necessary for normal development (Austin and Short, 1987).

The large volume of the oocytes cytoplasm contains essential materials for the progress of cleavage to the 2-cell stage and probably for subsequent divisions up to the eight-cell stage. It is at approximately the eight-cell stage that the embryo shows a quantitative increase in its biosynthetic capacity and the net synthesis of RNA and protein increases and transport of amino acids and nucleotides into the cells rises (Johnson and Everitt, 1980). At the 16-cell stage a process of compaction occurs. The morphological manifestation of compaction is the loss of clear cell outlines as the cells flatten against one another to maximize contact and specialised junctions between the cells develop for the first time (Johnson and Everitt,1980). Gap junctions and focal tight junctions form and the tight junctions become zonular and provide a permeability seal between the core of the embryo and the external environment (Johnson and Everitt, 1980). 
Two distinct features of the embryo's development are activation and cleavage of the fertilized egg and differentiation of the embryonic cells into inner cell mass and trophectoderm at the blastocyst stage (Paria and Dey, 1990). The embryo develops from the inner cell mass and the surrounding trophectoderm gives rise to the ectoderm of the placenta (Paria and Dey, 1990). The formation of the blastocoelic fluid involves the active transport of ions and possibly other solutes across the trophoblast wall (Mastroianni and Biggers, 1981).

The ability of preimplantation mammalian embryos to develop in simple culture media containing only a balanced salt solution and an energy source, suggested the existence of autocrine production of growth factors. However, these embryos demonstrated a developmental lag and developmental "blocks". These were overcome by co-culture with cells from the reproductive tract or by addition of growth factors and this led to the suggestion that the embryo coordinately expresses receptors for autocrine growth factors, as well as receptors for paracrine factors that are found within the reproductive tract (Heyner et al., 1993). Early development reflects a finely tuned series of interactions between the cells of the embryo and autocrine and paracrine factors (Heyner et al., 1993). So, although certain factors of embryonic origin participate in an autocrine regulation of embryonic development, the full complement of preimplantation embryo development requires additional paracrine factors that originate from the reproductive tract (Paria and Dey, 1990).

The free-living blastocyst is bathed in the secretions of the uterus and draws the oxygen and metabolic substrates that it requires for continued growth and survival from them. The embryo actively accumulates organic molecules and ions by cellular transport mechanisms, whilst exchange of $\mathrm{O}_{2}$ and $\mathrm{CO}_{2}$ is diffusional (Johnson and Everitt, 1980). The blastocyst has a high degree of metabolic selectivity and actively controls the rate of entry of substances from the surrounding uterine fluid (Austin and Short, 1984).

The embryo is implanted when it establishes physical contact with the uterus where embryonic tissue specialized for interaction with the uterus (trophoblast cells) and specialized attachment areas in the uterus (caruncles) become areas of integrated embryonic and maternal tissue (the cotyledons) which nourish the developing embryo (Austin and Short, 1987). 


\subsection{IN VITRO REPRODUCTION}

"In vitro" refers to events occurring outside of the animal. It is possible to mimic conditions that occur when an embryo is produced in vivo and it should be possible to create an embryo in vitro. The first step is to obtain a mature oocyte (in vitro maturation). This is then fertilized (in vitro fertilization) and cultured (in vitro culture) for 7 days to the blastocyst stage. No development occurs past the blastocyst stage of the embryo in vitro and it should be transferred to a recipient or frozen for later transfer.

The in vitro production of bovine embryos:

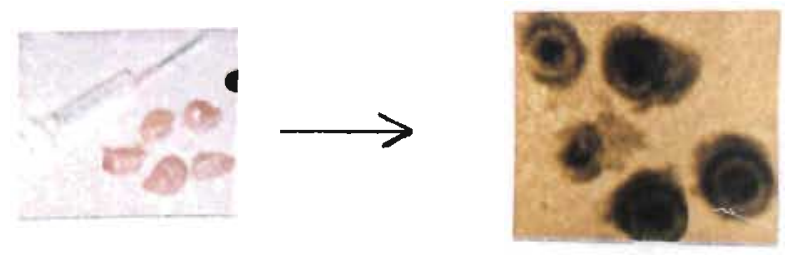

Immature oocytes are collected from ovaries of dead animals

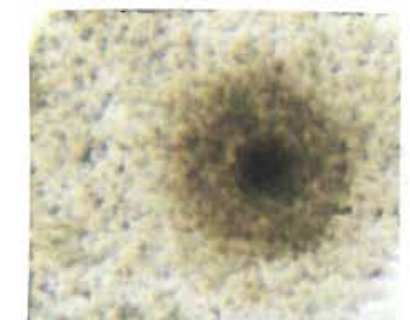

Matured in maturation medium for 24 hours

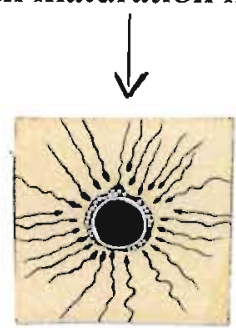

Fertilized with frozen/thawed semen for 18 hours

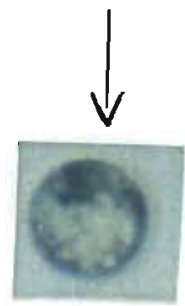

Cultured in culture medium for 7 days and a blastocyst is obtained for transfer or freezing 


\subsubsection{Oocyte recovery, selection and in vitro maturation}

Studies on the in vitro maturation of mammalian oocytes were reported some 61 years ago, when Pincus and Enzmann observed in 1935, that rabbit primary oocytes resumed meiosis spontaneously when they were liberated from vesicular follicles and placed in a suitable tissue culture medium (Gordon, 1994). Oocytes cultured within their follicles in vitro showed that an inhibitory factor was present in the follicle, which disappears on release of the oocyte (Gordon, 1994). Although it has been recognized for many years that oocytes will resume meiosis spontaneously in a suitable culture medium, it has also been known that, after apparently normal nuclear maturation, they may be quite incapable of giving rise to a normal embryo, unless the critical structural and biochemical changes that constitute maturation have occurred, and this means that culture conditions should ideally mimic in vivo conditions.

Recovery of bovine oocytes by aspiration of follicles, using a syringe and needle is the method most commonly employed (Figure 1a and 1b), but follicle dissection could also be used, which enables more oocytes to be recovered (Gordon, 1994). Follicle aspiration is advantageous as it is fairly easy and fast. The ability to visually assess and identify good quality oocytes is of considerable importance as poor quality oocytes have low fertilizing percentages. Hawk and Wall (1994a) showed a clear relationship between oocyte morphology and embryo yield after IVM/IVF/IVC. Reduced development was observed for the oocytes with poor or no cumulus cells. The percentage of development to blastocysts was higher for the oocytes with intact cumulus cells (Yang and Lu, 1990). If the oocyte has a sparse, clumpy or discoloured cumulus or it is naked of cumulus cells it is not chosen for maturation. A good oocyte most capable of normal maturation and further development has a complete well layered, compact, cumulus cell investment and evenly granulated cytoplasm (Hawk and Wall, 1994a) Oocytes can be broadly categorized into those which are acceptable for IVM and those that are not (Figure 2a and $2 \mathrm{~b}$ ). It is important to select a population of aspirated oocytes that will be expected to yield above average proportions of blastocysts (Hawk and Wall, 1994a).

The maturation procedure commonly employed for bovine oocytes involves the culture of selected oocytes in a suitable culture medium at $38.5^{\circ} \mathrm{C}$ (cattle have an average rectal temperature of $38^{\circ}$ $39^{\circ} \mathrm{C}$ ), in a $5 \% \mathrm{CO}_{2}$ atmosphere under humidity for 24 hours as the time of abstriction of the first polar 
body is 18 to 24 hours after the start of maturation (Gordon, 1994). After maturation an oocyte has an expanded and clear cumulus cell mass (Figure $3 \mathrm{a}$ and $3 \mathrm{~b}$ ) and the dispersion of the cumulus oophorus from the egg surface is thought to help in permitting penetration by spermatozoa (Mastroianni and Biggers, 1981).

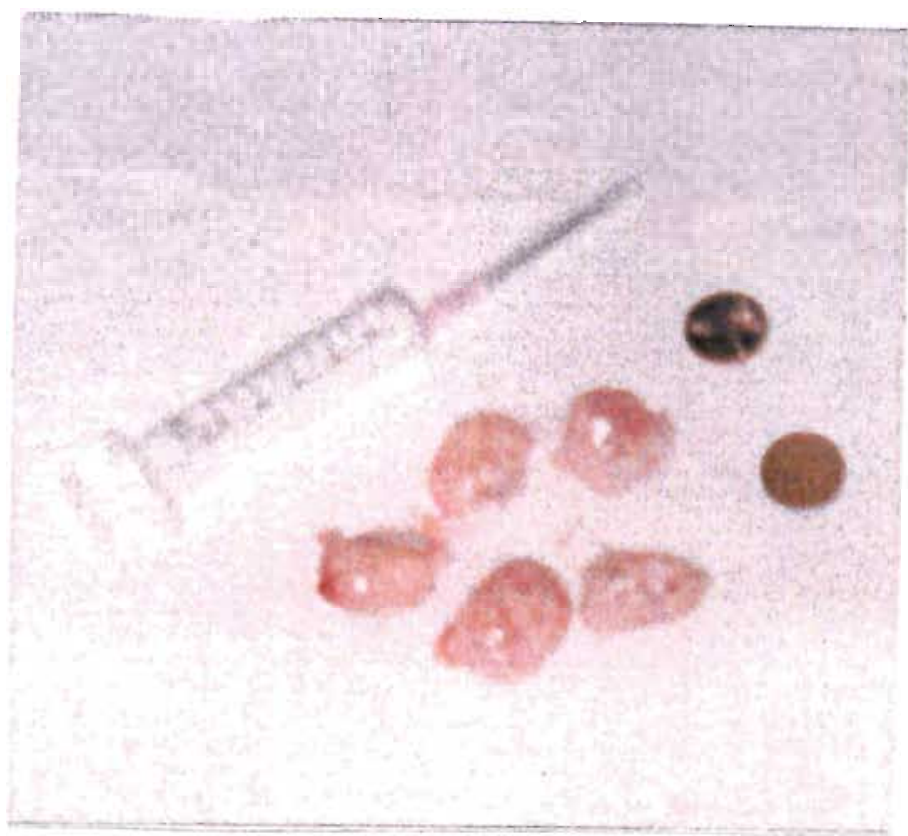

Figure 1a - A 10ml syringe and sample of ovaries (next to 5 cent coins for size comparison)

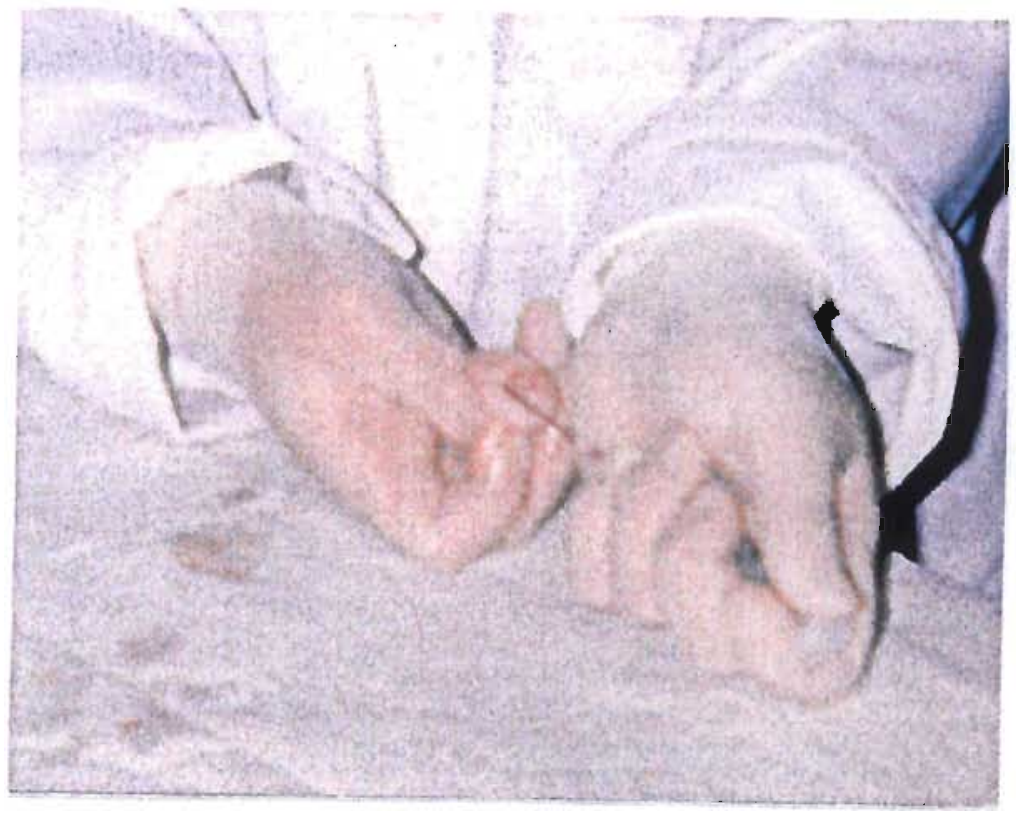

Figure $1 \mathrm{~b}$ - An example of an ovary being aspirated, follicular fluid is sucked into the syringe 


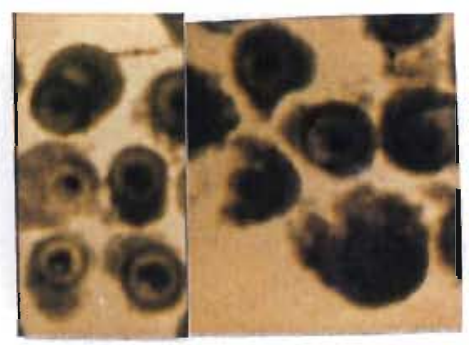

Figure $2 a$ - Oocytes of good quality with several compact cumulus layers

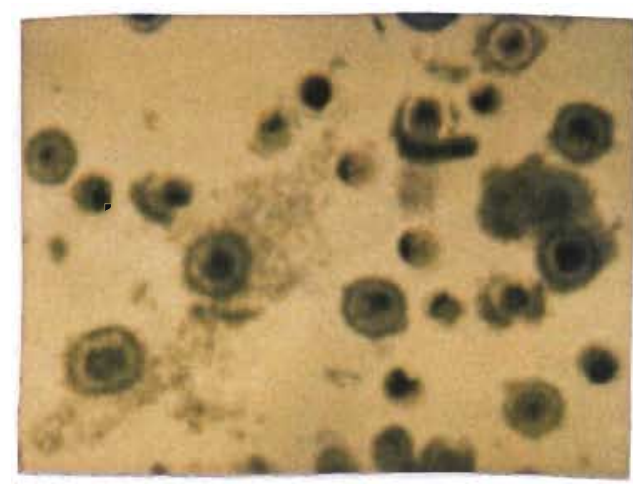

Figure $2 \mathrm{~b}$ - Oocytes of bad quality that are naked (no cumulus cells present) or have a spotty expanded cumulus

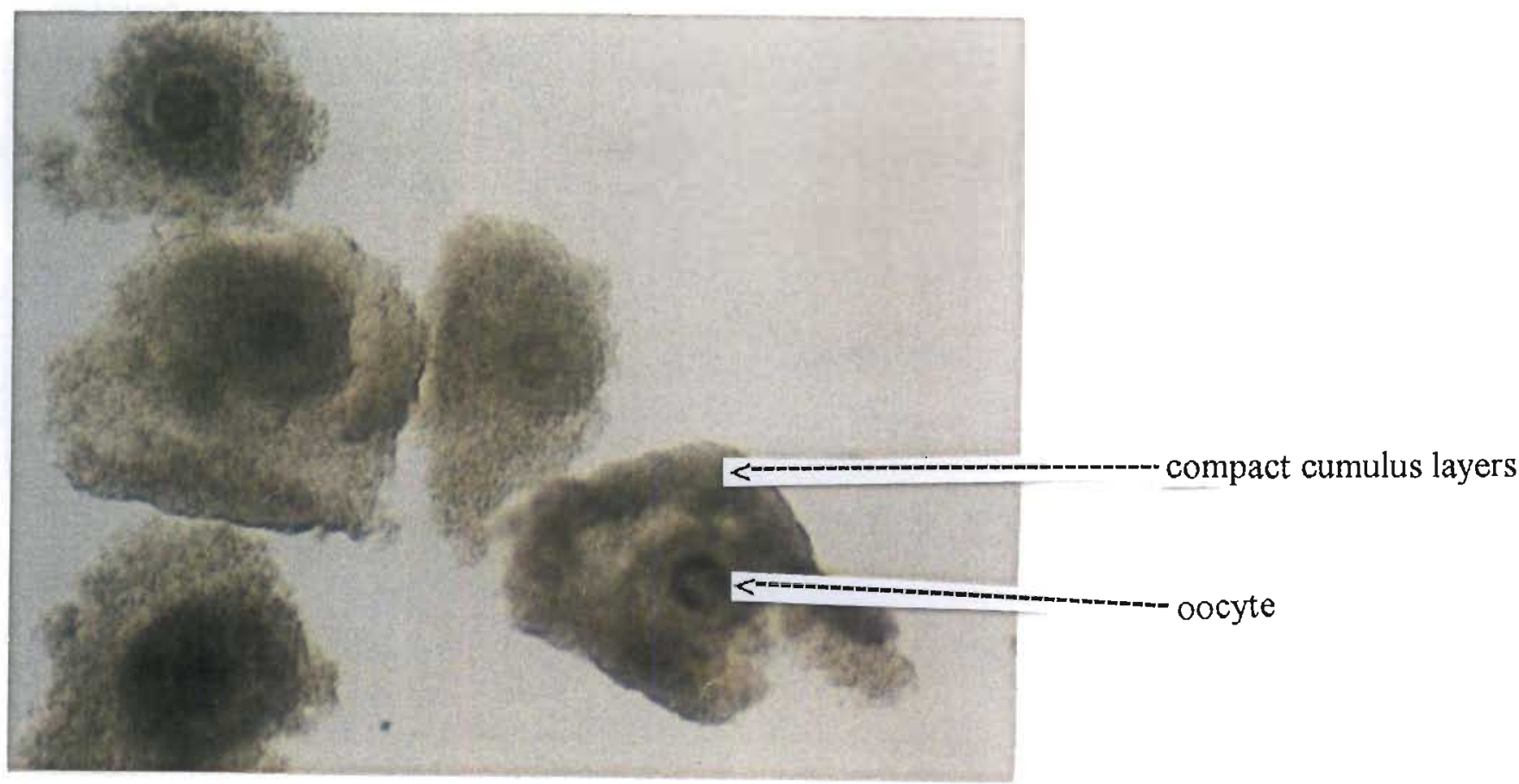

Figure 3a - Oocytes before maturation with compact cumulus cell layers 


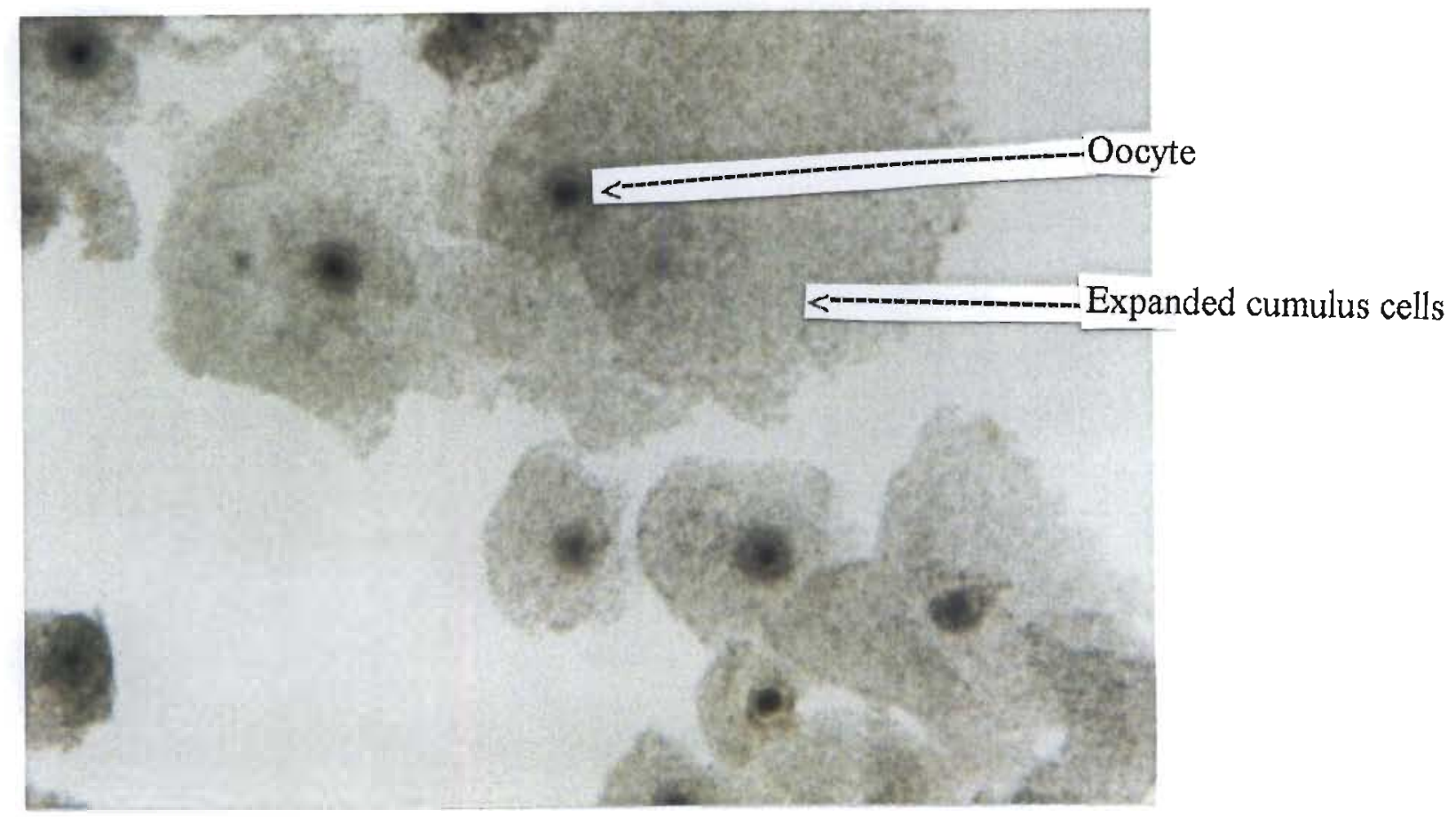

Figure $3 b$ - Oocytes 24 hours after maturation where the cumulus cell layers have expanded and the oocytes are ready for fertilization.

\subsubsection{In vitro fertilization}

With in vitro fertilization the male and female gametes are brought together in a suspending medium that is intended to provide satisfactory conditions for sperm penetration and for fertilization to occur. The culture medium provides the milieu for essential changes to occur in spermatozoa (ie. capacitation and the acrosome reaction) and supports the fertilization process itself (Mastroianni and Biggers, 1981). Artificial capacitation procedures are aimed at stimulating the sequence of events which normally occurs in the cow's reproductive tract (Gordon, 1994). Sperm can be capacitated by several forms of manipulation involving various types of media. The function of such manipulations is to remove the surface proteins from sperm which otherwise inhibit capacitation (Gordon, 1994). Bowles, 1996. 
A simple and successful technique for IVF consists of placing a drop (50 $\mu$ l) of culture medium in a plastic petri dish, covering it with a layer of mineral oil, equilibrating with $5 \% \mathrm{CO}_{2}$ in air and then adding oocytes and spermatozoa. This is then incubated for 18 hours at $38.5^{\circ} \mathrm{C}$. A commonly used medium is Tyrodes solution, a simple balanced salt solution (this contains the major ions found in blood in the correct proportions) supplemented with energy substrates and protein (BSA) (Gordon, 1994). Modified Tyrodes solution has improved culture conditions and contains lactate and pyruvate (Mastroianni and Biggers, 1981).

When in vivo fertilization occurs in the oviduct the sperm:oocyte ratio is close to one (Gordon, 1994). However, in IVF, the commonly used sperm doses vary from 0.5 to 5.0 million sperm $/ \mathrm{ml}$. The use of 1 million sperm/ml is recommended (Gordon, 1994. Polyspermy can occur when a high number of spermatozoa are in contact with an oocyte and can be enhanced by an aged oocyte (Gordon, 1994). An oocyte has a short lifespan after maturation and an oocyte matured for 32 hours has reduced defences against polyspermy as its cortical granules start to disperse instead of remaining at the surface and activating zona pellucida hardening (Austin and Short, 1982). Also, the time interval during which sperm and oocytes are incubated in the fertilization medium is important. When this interval is 24 hours compared to 18 hours, there is a significantly higher incidence of polyspermy (Chian et al, 1992 ). During IVF the cumulus cells are dispersed, by the release of enzymes (from the spermatozoa) to aid fertilization (Figure 4) (Austin and Short, 1982).

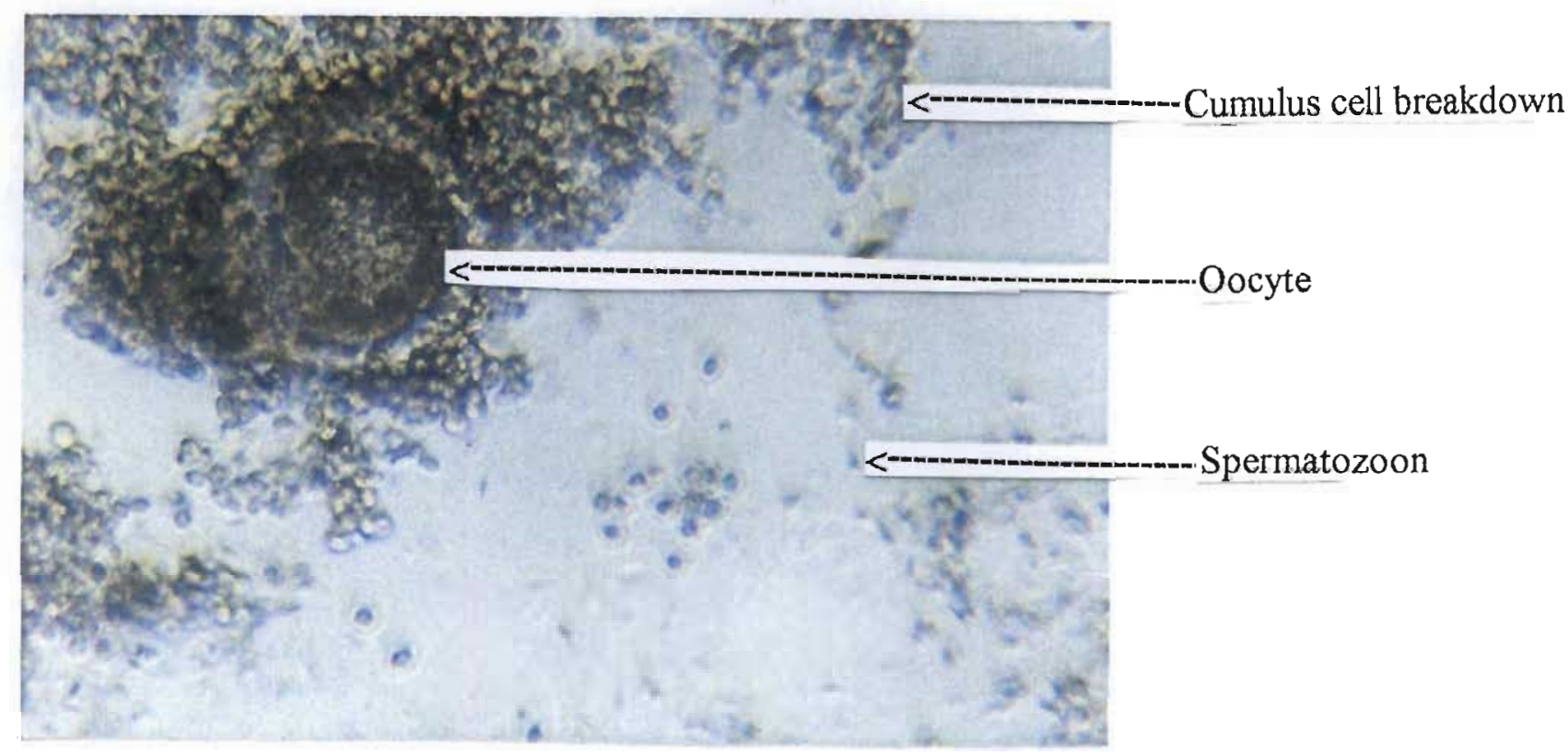

Figure 4 - An oocyte one hour after fertilization. Cumulus cell layer breakdown is noticeable. 


\subsubsection{In vitro culture}

It is possible to nurture the embryonic development from the zygote to the blastocyst stage in vitro for several mammalian species, including the cow, but this requires an appropriate environment. The problem of providing embryos with optimal nutrients is confounded by their hardiness, stage of development, the physical conditions that prevail and interacting influences of various constituents of the culture media (Mastroianni and Biggers, 1981).

The composition of early embryo culture media was based on a simple salt solution with energy sources such as pyruvate, glucose and lactate; supplemented with a protein source such as FCS or BSA (Gordon, 1994). There is a change in energy substrate requirements as oocytes and 2-cell stage embryos need pyruvate and lactate, but the 8-cell stage embryo and older is able to develop and survive using glucose (Gordon, 1994). This process of biochemical differentiation during cleavage may be related to an alteration in the ultrastructure of the mitochondria (Austin and Short, 1987). At the morula stage there is a shift from the hexose monophosphate oxidation pathway to a more efficient Embden-Meyerhof pathway and tricarboxylic acid (TCA) cycle. When the embryo reaches the blastocyst stage (time of implantation), energy source requirements and energy metabolism are similar to those of most adult cells (Austin and Short, 1987). Mastroianni and Biggers (1981) found that inclusion of BSA and amino acids improved development due to stabilization of the membranes, removal of toxic metal ions present in the culture medium or as a means of adding unidentified nutrients to the medium. Optimum levels of potassium, calcium, magnesium and phosphate are similar to levels found in serum (Mastroianni and Biggers, 1981). A simple medium that supports cow embryo development in vitro is Charles Rosenkrans 1 (CR1) with the addition of essential and non-essential amino acids (CRlaa).

Several criteria have been taken as endpoints for assessing embryo development in vitro. These include i) development to morula or blastocyst stages on day 6 or 7 , respectively, with grading of the embryo according to cell colour and quality, ii) normal cleavage taken to include symmetrical characteristic appearance comparable to that normally observed when in the oviduct, iii) positive viability as reflected by fluorescent staining after successive cleavages in culture and iv) normal development after transfer of in vitro cultured embryos to a recipient female (Mastroianni and Biggers, 1981). Methods (i) and 
(iv) are preferred because these are less likely to include parthenogenic oocytes and the ultimate endpoint for commercial purposes is a resultant calf. Parthenogenesis is defined as the development of the oocyte without the intervention of the male gamete. In general, the activated oocyte seldom cleaves more than twice before ceasing development (therefore early cleavage is not a sufficient measure of embryo quality). The cleavage rate is below that for oocytes exposed to sperm in the normal way and if an activated oocyte were to reach the blastocyst stage it does so at a much later stage (Gordon, 1994). That is why in method (i) blastocysts are evaluated on day 7 (Figure 5a and 5b) and not later, at day 9 for example, where the possibility exists of including parthenogenic oocytes.

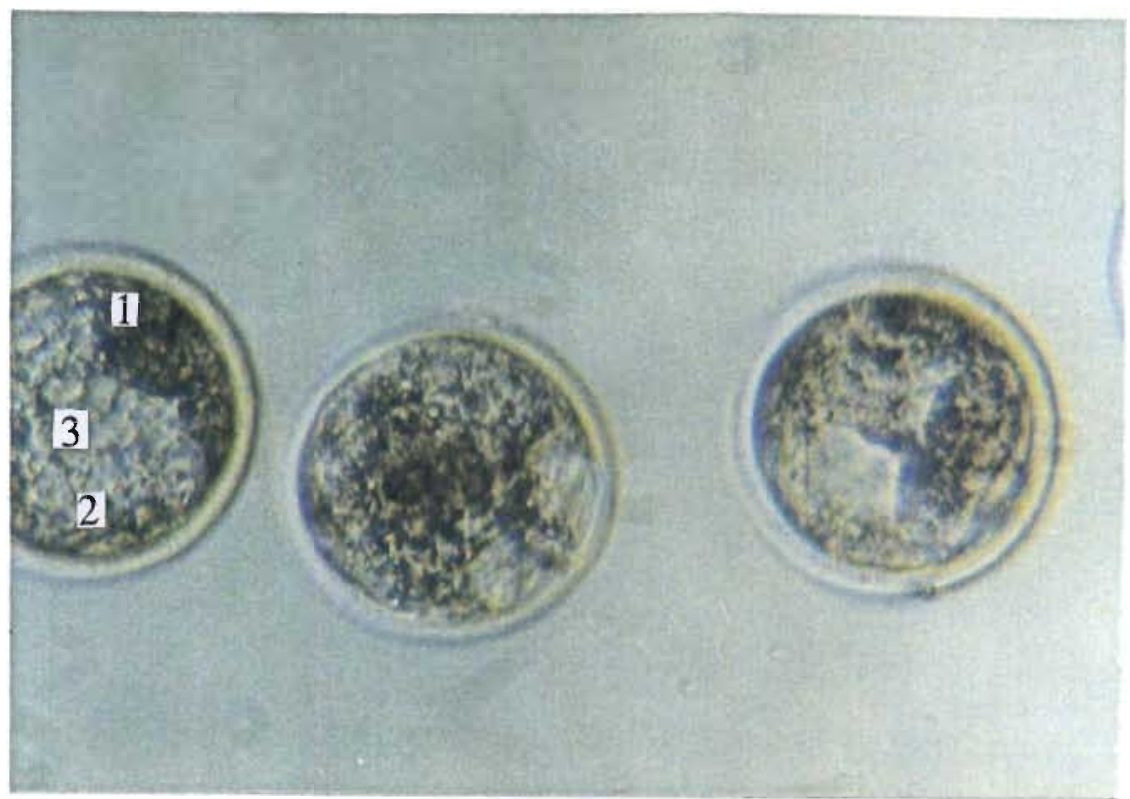

Figure 5a - Blastocysts from IVM/IVF/IVC evaluated on day 7.

Point 1 denotes the inner cell mass which becomes the embryo; point 2 denotes the trophectoderm cells which become the placenta; point 3 denotes the blastocoel. 


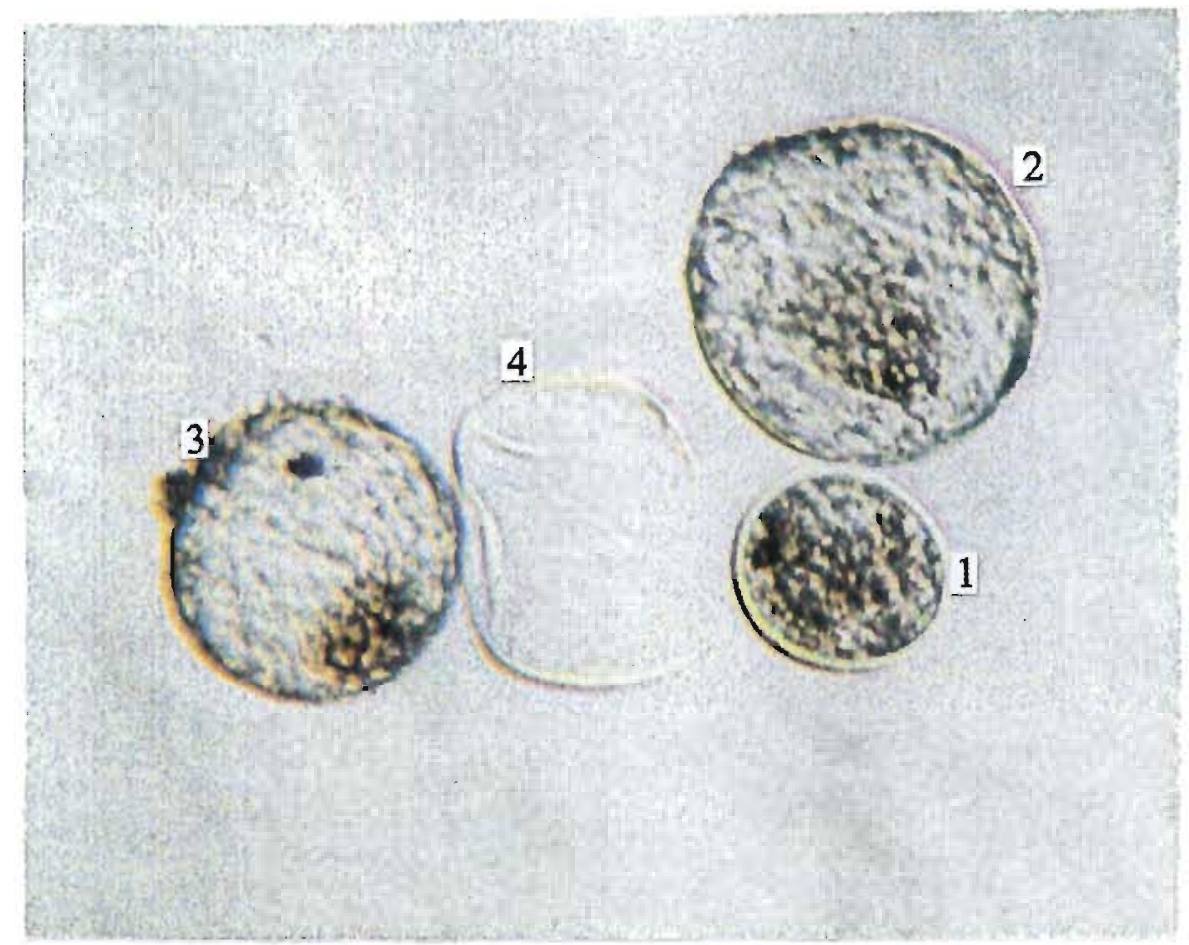

Figure $5 b$ - IVC blastocysts on day 8 where further development has occurred.

A blastocyst (point 1) for comparison to, an expanded blastocyst (point 2), and a hatched blastocyst (point 3 ) with the empty zona pellucida adjacent (point 4). 


\subsubsection{Insulin}

Insulin and IGF's regulate the growth of many types of mammalian cells. Insulin plays a physiological role in the growth of bovine follicles in vivo and insulin stimulates glucose uptake, general metabolism and mitosis of cultured bovine granulosa cells (Peluso and Hirschel, 1987). Stubbings et al. (1990) showed that in granulosa cell culture, insulin induced the proliferation of cells (through its mitogenic activity) and synergised with FSH to stimulate progesterone biosynthesis, increased aromatase activity and induced the formation of functional $\mathrm{LH}$ receptors. The growth promoting actions of these polypeptides are mediated by binding of receptors on the cell membrane and receptors with primary binding specificity for the polypeptides have been identified on embryos (Zhang et al, 1994).

Insulin belongs to the peptide family. It is a protein, consisting of two polypeptide chains, linked by disulfide bonds. It is best known as the mammalian hormone secreted by the beta cells of the pancreas. Heyner et al. (1993) studied insulin as a growth factor and came to some general conclusions: i) Preproinsulin is the initial translation product of the mRNA, a 109 amino acid single-chain precursor. ii) Proinsulin is produced in the Golgi apparatus and proteolytic cleavage converts proinsulin to insulin. iii) The insulin-like growth factors -I and -II (IGF-I and -II) possess a high degree of amino acid sequence homology with insulin and similar tertiary structures. Insulin and the IGF's bind to cell surface receptors and their actions are receptor mediated. iv) The insulin and IGF-I receptors are structurally very similar, both consisting of a tetrameric receptor made up of two alpha and two beta chains linked by disulfide bonds. The IGF-II receptor has a very different structure. v) Insulin binds with high affinity to the insulin receptor and with lower affinity to the IGF -I receptor. IGF-I binds with high affinity to its own receptor and with lower affinity to the insulin receptor and IGF-II binds to its own receptor with high affinity to IGF-I receptor with low affinity and does not bind to the insulin receptor.

A strong expression of IGF peptides is retained in those tissues which continue to undergo rapid growth and differentiation eg. the ovary (Hill, 1989). Immunoreactive IGF-I is found in ovarian follicular fluid at nanomolar concentrations, with the highest concentrations seen in dominant and pre-ovulatory follicles (Oliver et al., 1989). Hill (1989) stated that IGF-I could be substituted for pharmacological concentrations of insulin and Caubo et al. (1989) and Stubbings et al. (1990) showed that insulin competed for, and can bind to, receptors for IGF-I. 
Insulin is very likely to be one of the maternal regulators of preimplantation development. Evidence that insulin plays an important role in early development comes from experiments in which mice or rats have been made insulin deficient and blastocysts collected from such diabetic mothers have fewer cells in the inner cell mass than normal counterparts (Zhang et al., 1994). Zhang et al. (1994) used a mRNA phenotyping technique of reverse transcription polymerase chain reaction to demonstrate that insulin receptor mRNA is present in rat oocytes, one-cell, two-cell, four-cell and eight-cell embryo's and blastocysts.

Insulin and IGF-I could influence early embryo development in endocrine or in paracrine fashions (Zhang et al, 1994). IGF-I can act directly on the oocyte or via the granulosa cells, since IGF-I is assumed to mediate the effects of FSH and oestrogen and to enhance LH mediated oocyte maturation by increasing the number of LH receptors (Herrler et al., 1992). Addition of insulin to the culture medium improves the development of rat preimplantation embryo's in vitro, but this action of insulin requires the presence of amino acids (Zhang et al., 1994).

Insulin is required to assist the entry of glucose into all cells and the embryo and foetus have an obligatory requirement for glucose (McClure, 1994). Insulin alters blastocyst glucose metabolism in vitro, an observation which was confirmed by the demonstration of insulin receptors at about the morula stage (Wood and Kaye, 1989). Insulin specifically increased mouse embryonic protein synthesis during and after compaction, the rate of morphological development of mouse embryos during their preimplantation period in vitro, blastocyst glucose transport rates and fetal growth rate of embryos transferred after culture (Wood and Kaye, 1989). However, Butler and Williams (1990) found that insulin did not significantly increase glucose uptake by preimplantation mouse blastocysts in vitro. Stubbings et al. (1990) tested insulin at concentrations of $1,10,100$ and $1000 \mathrm{ng} / \mathrm{ml}$ and found no significant effect on fertilization rates or morula formation. They suggest that it is possible that the requirements for insulin may have been satisfied by the indigenous concentration present in foetal calf serum (FCS) and also consider the possible degradation of insulin (Stubbings et al, 1990).

Eberhardt et al. (1994) showed that porcine embryos responded to the addition of insulin to the culture medium by significantly increasing the cleavage rate and number of cells in the embryo. Heyner et al. (1993) used gold labelled insulin in conjunction with high resolution microscopy to show that embryos 
internalized insulin through receptor mediated endocytosis. Receptor specific binding could be detected on the cells of the inner cell mass and trophectoderm. The inner cell mass cells express insulin receptors and the addition of insulin to cultures of mouse preimplantation embryos results in a significant stimulation of DNA, RNA and protein synthesis (Heyner et al., 1993). Pig blastocysts show an increased rate of protein synthesis in response to exogenous insulin (Heyner et al., 1993). In the bovine (Zhang et al, 1994) exogenous insulin enhanced maturation and development of in vitro fertilized oocytes. Eberhardt et al. (1994) found that insulin receptors were present in the eight-cell porcine embryo and were capable of functioning by the blastocyst stage. Heyner et al. (1993) used insulin alone and in combination with transferrin and sodium selenite to stimulate the development of the one-cell porcine embryo. All the treatment groups contained bovine serum albumin (BSA) fraction V. It is possible that the embryo requires a protein supplement, like BSA, for insulin to have a positive effect on blastocyst formation (Eberhardt et al., 1994).

The addition of insulin alone to serum free medium had little effect on rat embryo development in vitro, but insulin with amino acids acted synergistically to increase the rate of development (Takagi et al., 1991). It is clear that mouse sixteen-cell embryos possess specific receptor sites for insulin and that insulin increases protein synthesis in mouse embryos in vitro (Takagi et al, 1991). Takagi et al. (1991) also showed that the stimulation of protein synthesis by embryos was specific to insulin by experiments using an anti-insulin antibody and this stimulation is not due to utilization of insulin as anspecific protein source, since all culture media contained BSA (1mg/ml). Harvey and Kaye (1988) found that exposure to insulin stimulated $3 \mathrm{H}$-leucine incorporation by compacted eight-cell embryos, blastocysts and expanded blastocysts. Increase in 3H-leucine incorporation is consistent with insulin's stimulation of protein metabolism in target tissues. Stimulation of protein synthesis includes an increase in the transport of amino acids largely through the sodium dependent system which has been reported for mouse blastocysts (Harvey and Kaye, 1988). Insulin stimulates amino acid incorporation to levels much closer to those observed in freshly collected embryos than embryos developed in control medium in vitro (Harvey and Kaye, 1988). 


\subsubsection{Selenium}

Selenium was discovered in 1817 by Berzelium and Gahn in sediments from a sulfuric acid plant at Gripsholm, Sweden (Lamb et al., 1958). Interest in Se as a trace element has resulted mainly from its toxic effects upon animals, although within past years its role as an essential element at very low concentrations has been shown and then selenium was found to be essential in 1957. Thus, selenium is described as an essential micronutrient (Lamb et al,, 1958). Segerson et al. (1977) showed a beneficial effect of selenium administration on reproduction where soils are deficient in selenium. Se increased fertility rate and this could reflect an action at the cellular level to regulate free radical generation in the ovaries, spermatozoa, ovulated oocytes or embryos (Arechiga et_al, 1994). Evidence indicates that generation of free radicals is one potential cause of abnormal embryonic development and if so, Se could be acting at the level of the ovary, uterus, gamete or developing embryo to enhance pregnancy rate (Arechiga et al., 1994).

Reactive oxygen metabolites (free radicals) generated during normal metabolism can, if not controlled, impair health and performance of cows. The direct effects are peroxidative changes in membranes and other cellular components. Free radicals can disrupt several processes associated with reproductive function, including synthesis of steroids and prostaglandins, sperm motility and embryonic development. Given the potential role of products of oxygen metabolism in normal or pathological reproduction, administration of antioxidants might improve reproductive function. Two molecules involved in protection of animal tissues from free radicals and peroxide metabolites are vitamin $\mathrm{E}$ and $\mathrm{Se}$ (Arechiga et al., 1994). Selenium is a co-factor of the enzyme glutathione peroxidase that acts in aqueous intracellular and extracellular compartments to catalyse the destruction of peroxides (Arechiga et al., 1994). Glutathione peroxidase (from Se) removes superoxide and peroxides within cells. Peroxidative chains are initiated by reactive species escaping enzymatic degradation and are terminated by chain breaking antioxidants like glutathione peroxidase (Arechiga et al, 1994). Glutathione peroxidase acts by destroying hydrogen peroxide and fatty acid hydroperoxides. Its primary mechanism is degrading low levels of $\mathrm{H}_{2} \mathrm{O}_{2}$ in cells. It also acts on hydroperoxides of unsaturated fatty acids and so this enzyme plays an important role in protecting membrane lipids, thus the cell membranes, from oxidative disintegration. Glutathione peroxidase accounts for the apparent "antioxidant" effects of dietary selenium (Rotruck et al., 1972). 
Embryo's cultured in vitro are often exposed to higher levels of oxygen than physiological concentrations, possibly leading to oxidative stress (Olson and Seidel, 1995). The oxygen tension within the female reproductive tract is approximately $5 \%$ and embryo development in vitro is better under $5 \% \mathrm{O}_{2}$ than under air which contains $20 \% \mathrm{O}_{2}$ (Rieger, 1992). Reduction of $\mathrm{O}_{2}$ concentrations from $20 \%$ to $5 \%$ is beneficial for the development of the early bovine embryo (Liu and Foote, 1995). Antioxidants can be added to the culture medium to lower the oxygen tension to protect the embryos from free radicals (Tornesi et al., 1995).

Results of in vitro studies have shown that reduced oxygen derivatives can inflict cellular changes, including peroxidation of membrane lipids, inactivation of enzymes and DNA damage. These reactive species, known as free radicals, are by-products of aerobic metabolism. Damage can occur directly to the cell or through the autoxidation of the serum components (Elhassan and Wright, 1995). Another requirement for $\mathrm{Se}$ in the medium is related to oxygen tension as this element helps remove free radicals of oxygen.

Nasr-Esfahani and Johnson (1992) reported that there is a rise in reactive oxygen species such as hydrogen peroxide or lipid peroxides (lipid peroxidation is the oxidative degradation of membrane unsaturated fatty acids) (Staats et al, 1988)) in the late 2-cell embryo. This rise in reactive oxygen species is not observed in embryos of the same age recovered from the female tract. The rise in concentration of reactive oxygen species appears to be a response to in vitro culture that depends on the stage of development and might be related in some way to the 2-cell block. Reactive oxygen species such as $\mathrm{H}_{2} \mathrm{O}_{2}$ in conjunction with superoxide (O2.) can cause cell damage by promoting hydroxy radical (HO.) formation, a reaction catalysed by transitional metals such as iron (Nasr-Esfahani and Johnson, 1992). Elhassan and Wright (1995) added Se to maturation media at $0.2 \mu \mathrm{g} / \mathrm{ml}$ and $0.4 \mu \mathrm{g} / \mathrm{ml}$. These levels did not benefit in improving early development of IVM/IVF of bovine oocytes as measured by cleavage rate. They suggest that the high levels of fetal bovine serum (20\%) may have provided sufficient natural antioxidants to the system. 


\subsubsection{Transferrin}

Transferrin is an iron binding protein. It is colourless when devoid of iron which it may chelate with a maximum of two ferric atoms to form a salmon coloured compound (Lamb et al., 1958). Transferrin comes from blood serum and is responsible for iron transport from the sites of absorption to the cells where it is stored or utilized. The main site of transferrin synthesis is the liver, although it is synthesised in some other tissues in lesser amounts (Sanchez, et al., 1992). Transferrin is internalized into cells by a receptor transferrin complex which enters into the cell where it is internalized in a vesicle with acidic $\mathrm{pH}$. This acidification promotes the release of iron from transferrin and then the transferrin receptor complex is translocated to the cell membrane (Sanchez et al, 1992). One of the most important roles of proteins, other than growth factors in the extracellular fluid and culture medium, is the transport of metal ions to the cells. Transferrin is known to carry $\mathrm{Fe}^{3+}$ ions and binds to its own transferrin receptor and thus is incorporated into the cell to distribute $\mathrm{Fe}^{3+}$ ions into the cytoplasm. Therefore, transferrin may have its growth promoting effect by meeting the demand for $\mathrm{Fe}^{3+}$ ions in proliferating cells (Natsuyama et al., 1993). Iron plays an important role in cell growth and metabolism and all growing cells require iron for cytochromes, so it must be made available (Lamb et al., 1958). In addition to iron, transferrin also binds other metals; such as chromium, manganese, cobalt, copper and zinc (Prasad, 1978).

Transferrin has been found to be stimulatory in serum free medium for the growth of many cell types (Tornesi et al., 1995). Its key reactions in energy metabolism and DNA synthesis are catalysed by iron containing enzymes and it is known that transferrin, the major serum iron transport protein, is an obligatory growth factor for cells growing in vitro (Trowbridge and Lopez, 1982). Transferrin is taken up by cells by receptor mediated endocytosis and Nasr-Esfahani and Johnson (1992) found that mouse embryos at the blastocyst stage have a low density of transferrin receptors and that transferrin promotes the development of mouse embryos through the two-cell block in vitro. The two-cell block occurs when an embryo stops developing at this stage, despite apparent normal cleavage development. Uptake of transferrin into the blastocyst was shown to occur by both receptor mediated and nonspecific pathways, but neither pathway was used to a detectable extent by embryos before the eight-cell stage (Nasr-Esfahani and Johnson, 1992). 
A reason why iron can become dangerous to cells in vitro is that iron acts directly on lipids to magnify peroxidative damage once this has been initiated by free hydroxy radicals. So addition of certain iron chelators such as bovine apotransferrin to the culture medium promotes development through their chelating effects. Three possible mechanisms of action of transferrin were suggested: i) transferrin sequesters free traces of iron and thereby promotes development through the two-cell block via inhibition of hydroxy radical formation and lipid peroxidation, ii) transferrin facilitates the transport of iron (and possibly other transitional metals) into the embryo, thus overcoming a two-cell block due to iron deficiency or iii) transferrin serves as a growth factor in a manner that is independent of its iron carrying properties (Nasr-Esfahani and Johnson, 1992). Most laboratory chemicals and reagents contain traces of iron that are sufficient to catalyse oxygen radical formation. Transferrin could act at, or outside, the vitelline membrane (oocyte membrane) to prevent autocatalytic peroxidative damage to lipids, by preventing free radical formation by superoxides and by preventing hydrogen peroxide leaking from the cells and reducing levels of free iron and other transitional metals available for entry into the cells (Nasr-Esfahani and Johnson, 1992). Transferrin has been identified as one of the many protein constituents of follicular and ampullary fluids, but has not been shown to have any clear functional role during folliculogenesis, ovarian steroidogenesis or oocyte development (Nasr-Esfahani and Johnson, 1992).

It has been suggested that oxygen derived radicals, such as superoxide, may be involved in the normal process of ovulation, since the percentage of matured follicles ovulated can be reduced by superoxide dismutase and transferrin might sequester free traces of iron (with or without other transitional metals such as copper) to prevent damage to the oocyte by the conversion of the required superoxide to more damaging radicals (Nasr-Esfahani and Johnson, 1992). Transferrin acts both in vivo and in vitro as a chelator to prevent highly toxic hydroxy radical production and thereby free radical mediated damage to oocytes and preimplantation embryos. This function is especially important during the two-cell stage (Nasr-Esfahani and Johnson, 1992). Apotransferrin showed a significant increase in the four-cell and blastulation rates of embryos compared with that of the control group (Natsuyama et al, 1993). Natsuyama et al. (1993) found that apotransferrin showed prominent growth promoting activity in mouse embryos, due to its antioxidative action or to the removal of some free metal ions such as $\mathrm{Fe}^{3+}$. 


\section{CHAPTER 2}

\section{COMBINATIONS OF INSULIN, SELENIUM AND TRANSFERRIN THAT MAXIMISE MATURATION, FERTLIZATION AND CULTURE}

\subsection{INTRODUCTION}

\subsubsection{The selection of a bull for in vitro fertilization}

Semen collected for use in artificial insemination is routinely assessed for sperm concentration, sperm motility and abnormal morphology as these parameters have been shown to correlate with fertility (Gordon, 1994). Assessing sperm quality on the basis of the percentage of progressively motile sperm and the percentage of sperm showing normal morphology could possibly ensure optimum in vitro fertilization (IVF). There is considerable variability among bull spermatozoa in their ability to become capacitated and penetrate oocytes in vitro (Aoyagi et al, 1988) and it is important to minimize or eliminate the bull as a source of variability in the in vitro system. Shi et al. (1991) suggested that variation arising from individual bulls is due to their individual characteristics, so selection of a bull producing sperm with high fertilizing ability is an important factor in achieving successful and consistent IVF results.

A population of sperm with a high frequency of viable, motile, morphologically normal bull sperm may be isolated using a percoll gradient. In percoll density gradients, sperm are separated by equilibrium as sperm density is equal to that of the gradient and it is used on the assumption that sperm with good nuclear morphology are denser than inferior sperm and are selected in the higher-density fraction of the percoll gradient (Gordon, 1994).

Sperm capacitation and the acrosome reaction are necessary physiological events that enable the sperm cell to penetrate the zona pellucida of the oocyte to initiate the fertilization process (Austin and Short, 1982). Glycosoaminoglycans (or a heparin-like glycosaminoglycan) within the cow's reproductive tract promote destabilization of the sperm membranes, thereby effecting capacitation (Lee and Ax, 1984). 
In vitro conditions that alter the sperm surface and elevate the internal $\mathrm{pH}$ of the sperm cell (which results in the release of internal calcium stores), or agents that promote rapid uptake of calcium to result in a calcium increase, can effectively prepare frozen bull sperm for IVF. This has been achieved in heparin-containing media (Greve et al., 1984). Heparin causes an increase in intracellular calcium and a decrease in intracellular pH (Susko-Parrish et al., 1990). The heparin dosage for sperm capacitation is bull specific and affects IVF and subsequent embryo development. Parrish et al. (1986) and Niwa and Ohgoda (1988) found that a heparin level of $10 \mu \mathrm{g} / \mathrm{ml}$ gave optimum results, whereas Lu et al. (1987) successfully used a level of $100 \mu \mathrm{g} / \mathrm{ml}$. Heparin can be used as a preincubation sperm treatment or it can be added directly to the fertilization medium, without the sperm undergoing any pretreatment, with similar results (Gordon, 1994). Lower concentrations of heparin are effective with prolonged incubation intervals (Brackett and Zuelku, 1993). Optimal conditions require experimentation and may differ according to the bull used and other interacting factors. Before evaluations of the in vitro system for optimum blastocyst production could be made it was first necessary to find a suitable bull that could be used in all the IVF procedures. Once denoted suitable according to motility and morphology it was necessary to find the correct heparin dose for optimum fertilization rates.

\subsubsection{The addition of insulin-transferrin-selenium (ITS) to maturation medium}

The next step was to assess the effects of insulin-transferrin-selenium (ITS) addition to the maturation medium as this had shown promising results in earlier studies. It is well established that the culture conditions employed for IVM of mammalian oocytes can significantly influence IVF rates and subsequent embryonic development (Brackett and Zuelke, 1993). Oocyte maturation refers to the changes occurring in the oocyte which endow it with the potential to be fertilized and to undergo early embryonic development (Stubbings et al, 1990). Several attempts have been made to alter the maturation system to increase the percentage of oocytes reaching maturation. Finding an improvement in in vitro maturation methods means an increased yield of matured oocytes for fertilization which could also mean an increase in the number of embryos produced by in vitro methods. Most laboratories involved in research on in vitro oocyte maturation in bovines routinely use Tissue Culture Medium 199 as the basic IVM medium. Generally, this is supplemented with proteins, such as foetal calf serum (FCS) or bovine serum albumin (BSA), and hormonal combinations of FSH, LH and oestradiol- $\beta\left(\mathrm{E}_{2}\right)$. 
Present-day research has sought to simulate the environment in vivo, and thereby enhance in vitro development rates.

In somatic cell culture, ITS was found to be essential for many cell lines (Shamsuddin et al., 1994). Shamsuddin et al. (1994) then subsequently studied the effect of ITS supplementation on bovine embryo development. They showed that tissue culture medium supplemented with bovine serum albumin and insulin, transferrin and selenium (ITS) supports the development of in vitro matured and in vitro fertilized oocytes to the blastocyst stage with increased post-thaw viability. Jewgenow and Pitra (1993) showed that ITS has a non-specific effect on cell vitality and growth, while Herrler et al (1992) found that addition of ITS to the maturation and culture media can increase the number of morulae and blastocysts. In 1994 (unpublished) the author researched addition of unfiltered ITS to the maturation medium under a 96-well plate system and observed a significant increase in maturation rates and an apparent increase in the rate of fertilization. Since then, laboratory culture systems changed from the 96-well technique to the simpler microdrops under mineral oil technique and before further studies on IVF and IVC were carried out it was important to ascertain whether ITS would have a positive effect on maturation rates under new conditions.

\subsubsection{The addition of insulin, selenium or transferrin individually or in combination to maturation, fertilization or culture medium}

The classical microbiological approach to bacterial growth involves complex media from which components can be systematically removed to ascertain their importance. The paucity of mammalian oocytes and embryos coupled with early recognized inhibitory effects has led to the emphasis on the experimental approach beginning with simple media and striving to enhance the quality of embryonic development and the number of embryos produced by the addition of promising ingredients. A multitude of media and conditions have been used in attempts to overcome in vitro induced blocks in embryo development (Barnes and Eyestone, 1990). When looking to improve media conditions it is necessary to consider the contributions from the female reproductive tract which supplies the specific embryonic requirements. Cells of the oviduct were used in the first successful co-culture systems in sheep and cattle (Gordon, 1994). Not only oviductal cells, but a wide variety of other somatic cells are 
capable of providing an environment in which embryos can develop (Hawk and Wall, 1994b). However, in cattle and sheep, co-culture of embryos with oviductal cells has been the most successful (Barnes and Eyestone, 1990).

Co-culture systems can be difficult to standardize and inefficient to maintain. Optimal embryo culture systems are simple and non-complicated using chemically defined media soundly based on knowledge of embryo metabolism and on known embryo preferences for energy substrates and other essential nutrients. Identification and purification of some or all of the factors in oviduct cells might lead to the production of superior embryo culture systems. It would then be possible to provide for all those factors crucial for embryonic development.

The successes obtained when using co-culture could be because i) helper cells produce mitogenic substances for the embryos, ii) helper cells can metabolize or sequester embryo toxic substances from the culture medium and iii) through their antioxidant activity, helper cells are able to reduce oxygen metabolite levels that embryos are exposed to in culture (Kane et al., 1992). Proteins (eg. BSA and FCS) are thought to chelate embryo toxic substances in the media and therefore protect embryos (Gordon, 1994). Bovine embryos cultured in vitro may be susceptible to oxidative stress by exposure to high $\mathrm{O}_{2}$ levels and light during routine embryo manipulations. Selenium is a known antioxidant, transferrin is a chelator of some metals and insulin is a growth promoter. These substances could be important in media designed to replace co-culture. Therefore, an experiment was designed that would show the effects on embryo development when insulin, selenium or transferrin were added individually or in combinations to the maturation, fertilization or culture media. For comparison, in all the experiments there was a control group of oocytes where none of the above was added to the media. After researching the literature a level of $10 \mu \mathrm{g} / \mathrm{ml}$ for insulin and transferrin and $10 \mathrm{ng} / \mathrm{ml}$ for selenium was decided on (Eppig et al., 1986; Feng et al., 1988; Jiang et al., 1990; Takagi et al., 1991; Kobayashi et al, 1994; Elhassan and Wright, 1995; Bowles, 1996). 


\subsection{MATERIALS AND METHODS}

\subsubsection{Oocyte recovery}

Bovine ovaries were removed from culled cows and heifers (beef and dairy) at a local abattoir. The ovaries were removed within 30 minutes of slaughter and placed in saline $(0.9 \%, \mathrm{w} / \mathrm{v}$, sodium chloride) with antibiotics $\left(0.5 \mu \mathrm{l} / \mathrm{ml}\right.$ gentamycin), maintained between $33^{\circ}$ and $37^{\circ} \mathrm{C}$ in a thermoflask and transported to the laboratory within two hours of slaughter. All follicles less than six millimetres in diameter ie. before commitment to atresia (Gordon, 1994), were aspirated with a $10 \mathrm{ml}$ syringe fitted with an 18 gauge needle. The aspirate was placed in a $50 \mathrm{ml}$ centrifuge tube and kept in a water bath at $33^{\circ} \mathrm{C}$. The cellular content settled to the bottom and this was transferred to a petri dish containing M199Hepes (with $1 \mathrm{mg} / \mathrm{ml}$ bovine serum albumen, fraction $\mathrm{V}$ (BSA);0.2mM pyruvate; $25 \mu \mathrm{g} / \mathrm{ml}$ gentamycin and $5 \mu \mathrm{g} / \mathrm{ml}$ heparin) and examined under a microscope. Oocytes which exhibited an evenly granulated cytoplasm and which were completely surrounded by at least three layers of unexpanded cumulus cells were selected. These were washed three times in M199Hepes and then transferred to a petri dish containing TCM199 maturation medium.

\subsubsection{In vitro maturation procedure}

All oocytes were washed three times in maturation medium TCM199 (with 10\% FCS, $0.2 \mathrm{mM}$ pyruvate, $25 \mu \mathrm{g} / \mathrm{ml}$ gentamycin, $2.5 \mu \mathrm{g} / \mathrm{ml} \mathrm{LH}, 20 \mu \mathrm{g} / \mathrm{ml} \mathrm{FSH}$ and $1 \mu \mathrm{g} / \mathrm{ml} \mathrm{E}_{2}$ ). Ten oocytes were selected randomly and allocated to each $50 \mu \mathrm{l}$ drop of TCM199 under mineral oil and incubated at $38.5^{\circ} \mathrm{C}$ in a humidified incubator, under $5 \% \mathrm{CO}_{2}$ in air for 24 hours.

Experiment 1 was used to determine the optimum heparin levels to be used in later IVF. The method is dealt with under fertilization procedures (section 2.2.5). 
In Experiment 2, ITS was added at three different concentrations to the maturation medium and the effect on maturation rate was evaluated. Treatment 1 was the normal laboratory maturation medium and served as the control; Treatment 2 involved the addition of $20 \mathrm{nM}$ ITS containing $3.3 \mu \mathrm{g} / \mathrm{ml}$ insulin, $3.3 \mu \mathrm{g} / \mathrm{ml}$ transferrin and $3.3 \mathrm{ng} / \mathrm{ml}$ selenium; Treatment 3 incorporated the addition of $29 \mathrm{nM} \mathrm{ITS} \mathrm{(} 5$ $\mu \mathrm{g} / \mathrm{ml}$ insulin, $5 \mu \mathrm{g} / \mathrm{ml}$ transferrin and $5 \mathrm{ng} / \mathrm{ml}$ selenium) and for Treatment 4 the ITS level was $58 \mathrm{nM}$ (10 $\mu \mathrm{g} / \mathrm{ml}$ insulin, $10 \mu \mathrm{g} / \mathrm{ml}$ transferrin and $10 \mathrm{ng} / \mathrm{ml}$ selenium).

Experiment 3 was based on the findings of Experiment 2. The Experiment was divided into three parts. In Experiment $3 \mathrm{a}$, insulin at $10 \mu \mathrm{g} / \mathrm{ml}$, selenium at $10 \mathrm{ng} / \mathrm{ml}$ and transferrin at $10 \mu \mathrm{g} / \mathrm{ml}$ were added individually or in combination to the maturation medium. Table 1 shows the eight treatments used for Experiment 3. All treatments were added after filtration of the maturation medium through a $0.22 \mu \mathrm{m}$ filter. After 24 hours in maturation medium, oocytes were transferred to untreated fertilization medium for 18 hours and then untreated culture medium for 7 days and the effect on maturation rates, fertilization rates and blastocyst development was evaluated. In Experiment $3 \mathrm{~b}$ and $3 \mathrm{c}$ oocytes were matured in normal laboratory medium without any additional supplements and treatments were added to the fertilization medium (Experiment 3b) or the culture medium (Experiment 3c).

Table 1: Treatments used in Experiment 3

\begin{tabular}{|c|c|}
\hline Treatment 1 & control \\
\hline Treatment 2 & selenium and transferrin \\
\hline Treatment 3 & insulin and transferrin \\
\hline Treatment 4 & insulin and selenium \\
\hline Treatment 5 & insulin \\
\hline Treatment 6 & selenium \\
\hline Treatment 7 & transferrin \\
\hline Treatment 8 & insulin, selenium and transferrin \\
\hline
\end{tabular}




\subsubsection{Maturation controls}

To determine the number of oocytes matured after 24 hours in maturation medium, a random sample of oocytes was not fertilized, but the oocytes were transferred in a small amount of medium to a clean slide after being vortexed to remove all cumulus cells. The slide was mounted and transferred to a Coplin jar containing acetic acid and ethanol (1:3) for a period of 24 hours, for fixation. The slide was then stained with aceto-orcein (2\%) and examined under a microscope. An oocyte was considered to be matured if it exhibited a metaphase plate and a polar body, indicating that the oocyte is at metaphase II of meiosis (Figure 6).

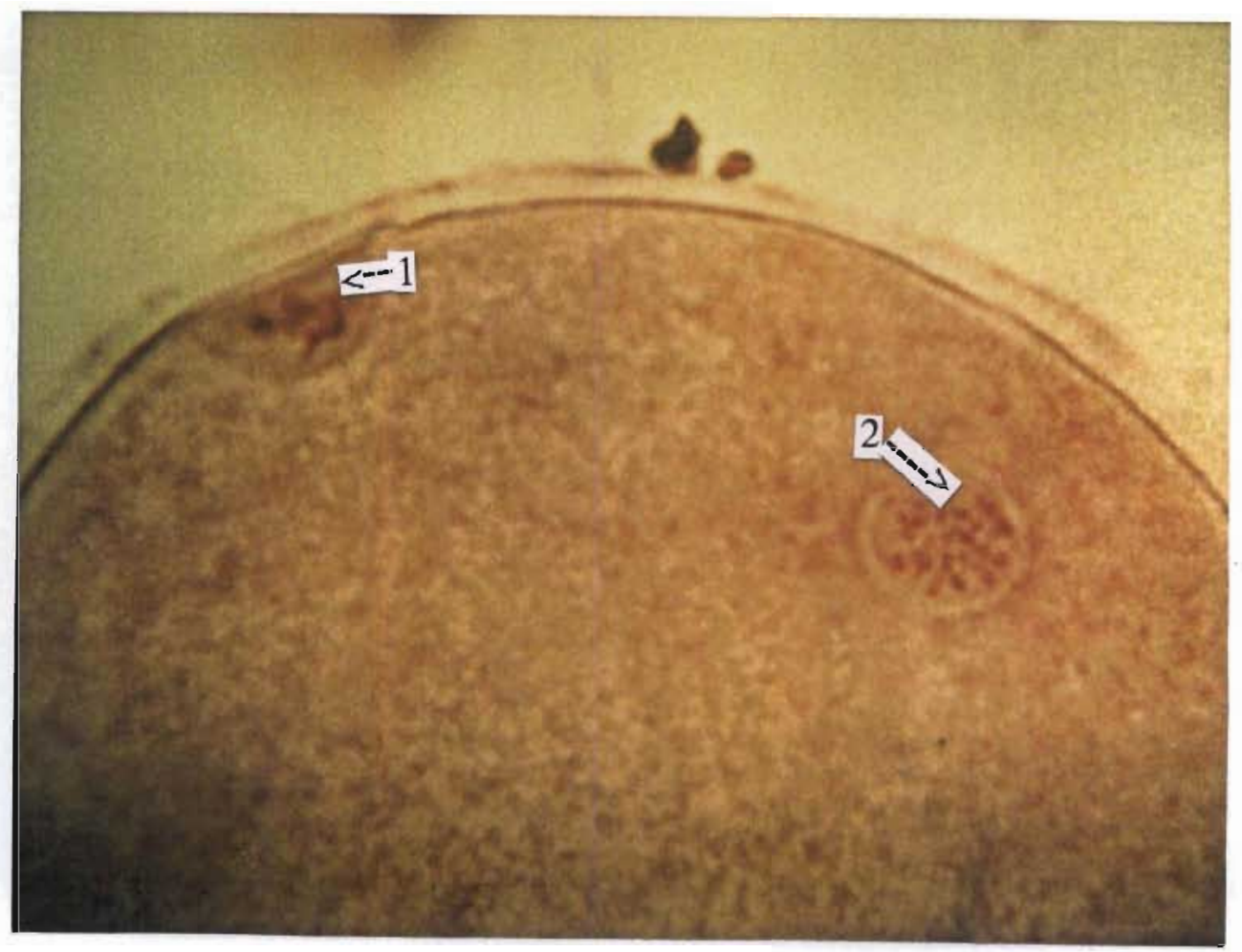

Figure 6 - A matured oocyte showing 1) a membrane-bound polar body and 2) metaphase chromosomes. 


\subsubsection{Assessment of sperm motility and morphology}

The semen of three bulls (from Taurus) were compared by visual assessment using an evaluation form as in Appendix 2. Semen characteristics are often associated with fertility levels, thus semen showing low sperm progressive motility, low sperm density or high percentages of abnormalities based on morphological appearance is not acceptable for IVF.

Table 2: Assessment of three A.I. bulls on sperm motility and morphology

\begin{tabular}{|c|c|c|c|}
\hline Bulls & Live spermatozoa & Progressive motility & Abnormal morphology \\
\hline 1260 & $40 \%$ & $30 \%$ & $20 \%$ \\
\hline 1205 & $50 \%$ & $40 \%$ & $20 \%$ \\
\hline FR 1792 & $70 \%$ & $60 \%$ & $10 \%$ \\
\hline
\end{tabular}

Based on the results in Table 2 it was decided to use bull FR1792. The progressive forward motility was high (60\%) with a low (10\%) percentage of abnormal spermatozoa and therefore a high number of viable sperm. Nothling and Arndt (1996) standardize good quality frozen-thawed semen, as that with more than $35 \%$ progressively motile sperm and less than $15 \%$ sperm with major defects. Bull FR 1792 was used in all IVF procedures to limit variation due to bull effects.

\subsubsection{In vitro fertilization procedure}

In vitro fertilization was performed using frozen semen from a single ejaculate of bull FR1792. After 24 hours of in vitro maturation, oocytes were pooled and washed in fertilization media and then groups of ten oocytes were randomly selected and transferred to $50 \mu \mathrm{l}$ drops of fertilization medium under mineral oil. The fertilization medium consisted of modified Tyrode's-lactate medium supplemented with $0.2 \mathrm{mM}$ pyruvate, $6 \mathrm{mg} / \mathrm{ml}$ fatty acid free bovine serum albumin (BSA) and $25 \mu \mathrm{g} / \mathrm{ml}$ gentamycin. The semen was thawed in water at $35^{\circ} \mathrm{C}$ and then placed on a percoll gradient $(45 \%, 90 \%)$ and centrifuged at $2600 \mathrm{rpm}$ for ten minutes. 
In Experiment 1 three levels of heparin were added to the fertilization medium to evaluate the optimum level of heparin to use with bull FR1792. Treatments 1, 2 and 3 were heparin at a final concentration of 5,10 and $20 \mu \mathrm{g} / \mathrm{ml}$ respectively. Once an optimum heparin level was found it was used at that level in all IVF procedures. In Experiment $3 \mathrm{~b}$ insulin, selenium and transferrin were added individually or in combinations to the fertilization medium at a concentration of $10 \mu \mathrm{g} / \mathrm{ml}, 10 \mathrm{ng} / \mathrm{ml}$ and $10 \mu \mathrm{g} / \mathrm{ml}$ respectively. Treatment $1,2,3,4,5,6,7$ and 8 were the same as for maturation treatments and all were added after filtration of the fertilization medium. After 18 hours, oocytes were transferred to untreated culture medium. The effect on fertilization rates and blastocyst development was evaluated.

At the time of insemination, $5 \mu \mathrm{l}$ of final concentration heparin, $5 \mu \mathrm{l} \mathrm{PHE}(20 \mu \mathrm{M}$ penicillamine, $10 \mu \mathrm{M}$ hypotaurine and $1 \mu \mathrm{M}$ epinephrine) and $5 \mu \mathrm{l}$ of the final sperm suspension were added to each drop, resulting in a final concentration of $1 \times 10^{6}$ spermatozoa/ml of fertilization medium. Sperm was diluted after counting with a haemocytometer. Ten cumulus oocyte complexes were coincubated for 18 hours with spermatozoa at $38.5^{\circ} \mathrm{C}$ in a humidified incubator under $5 \% \mathrm{CO}_{2}$ in air. The presence of a mixture of penicillamine, hypotaurine and epinephrine (PHE) in IVF media has been found to increase sperm motility and the frequency of oocyte penetration (Leibfried and Bavister, 1982; Susko-Parrish et al, 1990). PHE speeds up the process of heparin capacitation and facilitates sperm penetration (SuskoParrish et al, 1990) and it was thus decided to include PHE in all IVF procedures.

\subsubsection{Fertilization controls}

For assessment of the number of oocytes fertilized a random sample of oocytes was not cultured, but was transferred to slides and mounted. The slide was then fixed for 24 hours and then stained with $2 \%$ orcein and examined under a microscope. An oocyte was considered to be normally fertilized if it exhibited two pronuclei and a minimum of one polar body (Figure 7). More than two of either of these was considered to constitute polyspermy. 


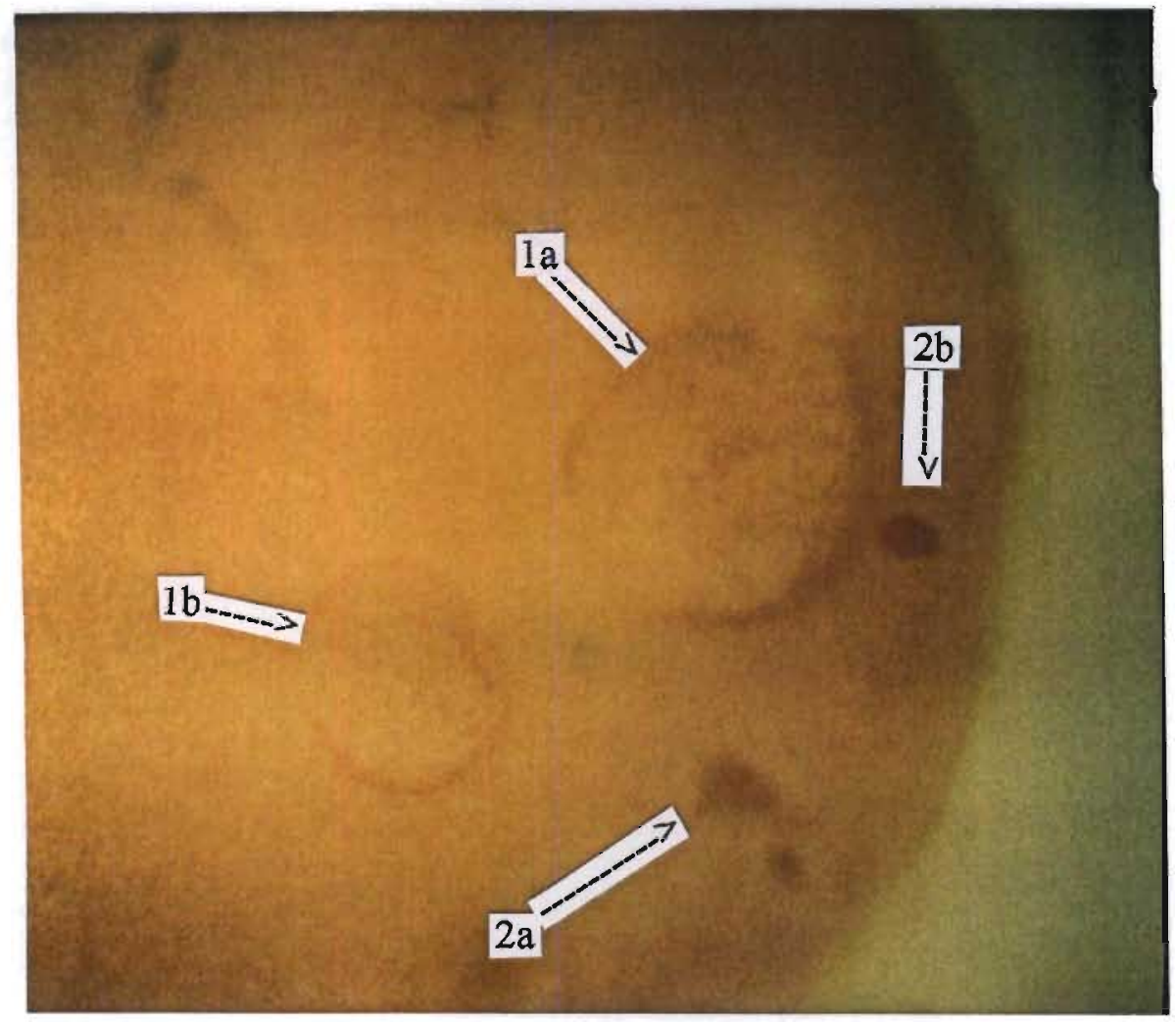

Figure 7 - Two pronuclei; $1 \mathrm{a}=$ female pronucleus (larger) and $1 \mathrm{~b}=$ male pronucleus, and two polar bodies ( $2 \mathrm{a}$ and $2 \mathrm{~b}$ ) in a fertilized oocyte. 


\subsubsection{In vitro culture procedure}

18 hours after addition of the spernatozoa the oocytes were placed in TCM199Hepes, vortexed for 2.5 minutes to remove all cumulus cells and then washed in CRlaa culture medium. Finally, they were placed in $50 \mu 1$ drops of $\mathrm{CR} 1$ aa under mineral oil and incubated in a humidified atmosphere of $5 \% \mathrm{CO}_{2}$ in air at $38.5^{\circ} \mathrm{C}$. For experiment $3 \mathrm{c}$ the same 8 treatments as for IVM and IVF were randomly assigned to each $50 \mu \mathrm{l}$ culture drop. The effect on blastocyst development was then evaluated. Initial cleavage ( $>2$ cells) was assessed 42 hours after insemination. Media were not changed during the course of incubation, but $5 \mu$ l of $10 \%$ FCS was added to each drop on day 4 of incubation. Criteria for normal development was attainment of the blastocyst stage by day 7 after insemination.

\subsubsection{Experimental design and statistical analysis}

Experiment 1 was designed to determine the heparin level best suited for bull FR1792 for the highest fertilization rates and blastocyst development. There were three treatments and three replicates. The treatments were randomly assigned to each $50 \mu 1$ droplet on a $60 \mathrm{~mm}$ Falcon petrie dish and 10 oocytes were randomly allocated to each drop. An analysis of variance, using Genstat, was carried out on the number of oocytes fertilized for each treatment and the number of blastocysts for each treatment.

Experiment 2 was designed to test the role of ITS in oocyte maturation medium, which was added after the normal procedure of filtering all media. There were four treatments (three ITS concentrations and a control with no ITS) and three replications. The treatments were randomly assigned to each drop on a $60 \mathrm{~mm}$ Falcon petri dish and ten oocytes were randomly allocated to each drop. An analysis of variance, using Genstat, was carried out on the number of matured oocytes for each treatment.

Experiment 3 was divided into three parts as the addition of insulin, selenium and transferrin; individually, or in combinations was added a) to the maturation medium, b) to the fertilization medium and c) to the culture medium. Experiment $3 \mathrm{a}$ assessed the effects on maturation rates and the subsequent development of bovine oocytes. Experiment $3 \mathrm{~b}$ assessed the effects on the fertilization rates 
and the subsequent development of bovine oocytes. Experiment $3 c$ assessed the effects on the development of the bovine embryo. There were 5 replicates for treatment 1 and 8, 10 replicates for treatment 2,3 and 4 and 20 replicates for treatment 5,6 and 7 in Experiment $3 \mathrm{a}$ and $3 \mathrm{~b}$. In Experiment $3 c$ there were 6 replicates for treatment 1 and 8,12 replicates for treatment 2,3 and 4 and 24 replicates for treatment 5,6 and 7. The treatments were randomly assigned to $50 \mu \mathrm{l}$ drops of each culture medium on a $60 \mathrm{~mm}$ Falcon petri dish and each drop contained 10 oocytes. An analysis of variance, using Genstat, was carried out on the number of oocytes matured, number fertilized and the number of blastocysts for each treatment.

\subsection{RESULTS}

\subsubsection{Bull selection}

For Experiment 1 the mean maturation rate of oocytes was $68 \%$, which is acceptable. Therefore, any variation in fertilization rates was not due to the inability of oocytes to mature. Bull effects were excluded by using the same bull and semen from the same ejaculate, so it can be assumed that differences in fertilization rates are due to the different heparin levels used. From the results summarized in Table 3 , it can be seen that the fertilization rate is significantly higher $(\mathrm{P}<0.05)$ for those oocytes where a heparin level of $10 \mu \mathrm{g} / \mathrm{ml}$ final concentration was used and the blastocyst rate is significantly higher $(\mathrm{P}<0.05)$ when IVF took place with $10 \mu \mathrm{g} / \mathrm{ml}$ final concentration of heparin. The polyspermy percentage of $9 \%$ at $20 \mu \mathrm{g} / \mathrm{ml}$ heparin level was within the acceptable range. 
Table 3: Fertilization rates and blastocyst development at different heparin levels added at IVF

\begin{tabular}{|c|c|c|c|c|}
\hline \multicolumn{1}{|c|}{ Treatment } & No. oocytes & \% polyspermy & \% fertilized & \% blastocysts \\
\hline $\mathrm{A}=5 \mu \mathrm{g} / \mathrm{ml}$ heparin & 100 & 6 & $65^{\mathrm{a}}$ & $10^{\mathrm{a}}$ \\
\hline $\mathrm{B}=10 \mu \mathrm{g} / \mathrm{ml}$ heparin & 100 & 6 & $71^{\mathrm{b}}$ & $18^{\mathrm{b}}$ \\
\hline $\mathrm{C}=20 \mu \mathrm{g} / \mathrm{ml}$ heparin & 100 & 9 & $65^{\mathrm{a}}$ & $13^{\mathrm{a}}$ \\
\hline
\end{tabular}

Values within a column with different superscripts are significantly different $(\mathrm{P}<0.05)$.

\subsubsection{Addition of ITS to maturation medium}

The results summarized in Table 4 are for Experiment 2. The maturation rate for oocytes matured with unfiltered ITS under each different system of culture is significantly higher compared to when no ITS is added $(\mathrm{P}<0.05)$. No significant difference was found between the various concentrations of ITS.

Table 4: IVM with unfiltered ITS in a 96-well plate culture system or in drops under mineral oil

\begin{tabular}{|c|c|c|c|}
\hline Treatment & Number oocytes & $\begin{array}{c}\% \text { matured in 96-well } \\
\text { plate system }\end{array}$ & $\begin{array}{c}\text { \% matured in drops } \\
\text { under oil }\end{array}$ \\
\hline A=control & 120 & $65^{\mathrm{a}}$ & $66^{\mathrm{a}}$ \\
\hline $\mathrm{B}=20 \mathrm{nM}$ ITS & 120 & $80^{\mathrm{b}}$ & $79^{\mathrm{b}}$ \\
\hline $\mathrm{C}=29 \mathrm{nM}$ ITS & 120 & $82^{\mathrm{b}}$ & $79^{\mathrm{b}}$ \\
\hline $\mathrm{D}=58 \mathrm{nM}$ ITS & 120 & $80^{\mathrm{b}}$ & $80^{\mathrm{b}}$ \\
\hline
\end{tabular}

Values within a column with different superscripts are significantly different $(\mathrm{P}<0.05)$. 


\subsubsection{Insulin, selenium and transferrin in the maturation, fertilization or culture medium}

Table 5 shows the results for Experiment $3 a$ where the treatments were added to the maturation medium. The effect on IVM, IVF and blastocyst development was evaluated using 1,200 oocytes. From the results in Table 5 it can be seen that the addition of Insulin significantly $(\mathrm{P}<0.05)$ increased the maturation rate compared to the control $(72.3 \%$ vs $61.8 \%)$. However, effects on fertilization and blastocyst production were not significant. Selenium added at $10 \mu \mathrm{g} / \mathrm{ml}$ to the maturation medium, significantly $(\mathrm{P}<0.01)$ increased the maturation rate $(80.8 \%$ vs $61.8 \%)$, fertilization rate $(68.0 \%$ vs $58.4 \%)$, cleavage rate $(72.6 \%$ vs $58.7 \%)$ and the blastocyst production rate $(24.6 \%$ vs $11.5 \%)$. Selenium also significantly $(\mathrm{P}<0.05)$ decreased the polyspermy percentage occurring during fertilization (9.8\% vs $11.9 \%)$. Insulin plus Selenium had no significant effect on maturation or fertilization rates, but did significantly $(\mathrm{P}<0.01)$ increase the percentage of oocytes cleaving $(75.0 \%$ vs $58.7 \%)$ and the number of blastocysts produced (18.0\% vs $11.5 \%)$.

Table 5: Development of oocytes when Insulin, Selenium or Transferrin is added to the maturation medium

\begin{tabular}{|c|c|c|c|c|c|c|c|}
\hline Treatment & $\begin{array}{c}\text { No. } \\
\text { oocytes }\end{array}$ & Reps & $\begin{array}{c}\% \\
\text { matured }\end{array}$ & $\begin{array}{c}\% \\
\text { polyspermy }\end{array}$ & $\begin{array}{c}\% \\
\text { fertilized }\end{array}$ & $\begin{array}{c}\% \\
\text { cleaved }\end{array}$ & $\begin{array}{c}\% \\
\text { blastocysts }\end{array}$ \\
\hline $1=$ control & 150 & 5 & $61.8 \pm 2.9$ & $11.9 \pm 1.1$ & $58.4 \pm 3.0$ & $58.7 \pm 9.1$ & $11.5 \pm 1.6$ \\
\hline $2=\mathrm{S}+\mathrm{T}$ & 150 & 10 & $86.3 \pm 2.5^{* *}$ & $13.5 \pm 1.5^{* *}$ & $49.1 \pm 2.3^{* *}$ & $75.0 \pm 2.5^{*}$ & $10.7 \pm 1.1^{* *}$ \\
\hline $3=\mathrm{I}+\mathrm{T}$ & 150 & 10 & $75.4 \pm 2.5$ & $9.1 \pm 1.5^{* *}$ & $60.5 \pm 2.3^{* *}$ & $65.6 \pm 2.5^{*}$ & $10.3 \pm 1.1^{*}$ \\
\hline $4=\mathrm{I}+\mathrm{S}$ & 150 & 10 & $80.8 \pm 2.5$ & $8.9 \pm 1.5$ & $58.4 \pm 2.3$ & $75.0 \pm 2.5^{* *}$ & $18.0 \pm 1.1^{* *}$ \\
\hline $5=\mathrm{I}$ & 150 & 20 & $72.3 \pm 1.8^{*}$ & $11.0 \pm 1.0$ & $50.6 \pm 1.6$ & $67.9 \pm 1.8$ & $11.7 \pm 0.8$ \\
\hline $6=\mathrm{S}$ & 150 & 20 & $80.4 \pm 1.8^{* *}$ & $9.8 \pm 1.0^{*}$ & $68.0 \pm 1.6 * *$ & $72.6 \pm 1.8^{* *}$ & $24.6 \pm 0.8^{* *}$ \\
\hline $7=\mathrm{T}$ & 150 & 20 & $72.9 \pm 1.8 *$ & $11.8 \pm 1.0$ & $48.5 \pm 1.6 * *$ & $68.8 \pm 1.8$ & $9.7 \pm 0.8^{* *}$ \\
\hline $8=\mathrm{I}+\mathrm{S}+\mathrm{T}$ & 150 & 5 & $90.0 \pm 4.0$ & $11.8 \pm 2.2$ & $65.6 \pm 3.0^{* *}$ & $71.6 \pm 5.9$ & $9.5 \pm 1.5$ \\
\hline
\end{tabular}

All values are mean \pm S.E.D.

* $\mathrm{P}<0.05$ compared with control value.

$* * \mathrm{P}<0.01$ compared with control value. 
For Experiment $3 b$ (Table 6) the treatments were added to the fertilization medium after IVM in untreated maturation medium. The effects on IVF and blastocyst development were evaluated, with 800 oocytes being used for the evaluations. The mean percentage of matured oocytes was $70 \%$. Insulin, Transferrin, Insulin plus Selenium and Insulin plus Transferrin significantly $(p<0.01)$ decreased the fertilization rates. The polyspermy rates for these four treatments were all increased. Selenium significantly $(p<0.01)$ increased fertilization rates. None of the treatments had an effect on the percentage of blastocysts produced.

Table 6: Influence of Insulin, Selenium or Transferrin when included in the fertilization medium

\begin{tabular}{|c|c|c|c|c|c|c|}
\hline Treatment & $\begin{array}{c}\text { No. } \\
\text { oocytes }\end{array}$ & Replicates & $\begin{array}{c}\% \\
\text { polyspermy }\end{array}$ & $\begin{array}{c}\% \\
\text { fertilized }\end{array}$ & $\begin{array}{c}\% \\
\text { cleaved }\end{array}$ & $\begin{array}{c}\% \\
\text { blastocysts }\end{array}$ \\
\hline $1=$ control & 100 & 5 & $15.9 \pm 5.0$ & $58.8 \pm 2.5$ & $62.6 \pm 6.5$ & $15.0 \pm 2.4$ \\
\hline $2=\mathrm{S}+\mathrm{T}$ & 100 & 10 & $20.8 \pm 3.6$ & $55.5 \pm 1.5$ & $60.4 \pm 5.0$ & $12.0 \pm 1.4$ \\
\hline $3=\mathrm{I}+\mathrm{T}$ & 100 & 10 & $30.8 \pm 3.6$ & $45.6 \pm 1.5^{* *}$ & $55.7 \pm 5.0$ & $12.0 \pm 1.4$ \\
\hline $4=\mathrm{I}+\mathrm{S}$ & 100 & 10 & $23.5 \pm 3.6^{*}$ & $45.0 \pm 1.5^{* *}$ & $68.1 \pm 5.0^{* *}$ & $13.0 \pm 1.4$ \\
\hline $5=\mathrm{I}$ & 100 & 20 & $25.4 \pm 2.6^{* *}$ & $45.3 \pm 1.1^{* *}$ & $59.2 \pm 3.5$ & $10.3 \pm 1.0$ \\
\hline $6=\mathrm{S}$ & 100 & 20 & $20.5 \pm 2.6$ & $69.5 \pm 1.1^{* *}$ & $64.0 \pm 3.5$ & $14.1 \pm 1.0$ \\
\hline $7=\mathrm{T}$ & 100 & 20 & $21.5 \pm 2.6$ & $46.2 \pm 1.1^{* *}$ & $57.5 \pm 3.5$ & $11.0 \pm 1.0$ \\
\hline $8=\mathrm{I}+\mathrm{S}+\mathrm{T}$ & 100 & 5 & $20.4 \pm 5.5$ & $53.3 \pm 2.5$ & $60.5 \pm 7.1$ & $11.7 \pm 2.3$ \\
\hline
\end{tabular}

All values are mean \pm S.E.D.

* $\mathrm{P}<0.05$ compared with control value.

** $\mathrm{P}<0.01$ compared with control value.

Table 7 shows the results for Experiment $3 \mathrm{c}$ where the treatments were added to the culture medium after IVM and IVF in normal laboratory media. The effect on blastocyst production was evaluated with 640 oocytes being analysed for IVC. The mean percentage of matured and fertilized oocytes was $71 \%$ and $68 \%$ respectively, and the mean percentage of oocytes exhibiting polyspermy was $7 \%$. The addition of Insulin significantly $(\mathrm{P}<0.01)$ decreased the number of blastocysts produced when added to the 
culture medium (Table 7). Addition of Transferrin or Insulin plus Selenium plus Transferrin significantly $(\mathrm{P}<0.05)$ increased the number of blastocysts produced $(35.3 \%$ and $31.5 \%$ vs $18.7 \%)$.

Table 7: Addition of Insulin, Selenium or Transferrin to the culture medium

\begin{tabular}{|c|c|c|c|c|c|}
\hline Treatment & $\begin{array}{c}\text { Number } \\
\text { oocytes }\end{array}$ & Replicates & \% cleaved & \% blastocysts & \% hatched \\
\hline $1=$ control & 80 & 6 & $62.3 \pm 1.7$ & $18.7 \pm 3.9$ & $14.2 \pm 2.3$ \\
\hline $2=\mathrm{S}+\mathrm{T}$ & 80 & 12 & $68.2 \pm 2.6^{* *}$ & $27.0 \pm 2.9$ & $16.4 \pm 3.1$ \\
\hline $3=\mathrm{I}+\mathrm{T}$ & 80 & 12 & $68.1 \pm 2.6^{* *}$ & $20.2 \pm 2.9$ & $9.2 \pm 3.1^{* *}$ \\
\hline $4=\mathrm{I}+\mathrm{S}$ & 80 & 12 & $60.0 \pm 2.6$ & $18.3 \pm 2.9$ & $22.5 \pm 3.1^{*}$ \\
\hline $5=\mathrm{I}$ & 80 & 24 & $70.5 \pm 1.9^{* *}$ & $17.7 \pm 2.0^{* *}$ & $15.9 \pm 2.2$ \\
\hline $6=\mathrm{S}$ & 80 & 24 & $70.1 \pm 1.9^{* *}$ & $23.4 \pm 2.0$ & $16.2 \pm 2.2^{*}$ \\
\hline $7=\mathrm{T}$ & 80 & 24 & $71.5 \pm 1.9^{* *}$ & $35.3 \pm 2.0^{*}$ & $21.9 \pm 2.2$ \\
\hline $8=\mathrm{I}+\mathrm{S}+\mathrm{T}$ & 80 & 6 & $69.5 \pm 4.1$ & $31.5 \pm 4.0^{*}$ & $18.4 \pm 5.0$ \\
\hline
\end{tabular}

All values are mean \pm S.E.D.

$* \mathrm{P}<0.05$ compared with control value.

** $\mathrm{P}<0.01$ compared with control value. 


\subsection{DISCUSSION}

\subsubsection{Bull selection}

The selection of a bull with a high fertilizing ability is an important factor in achieving successful and consistent IVF results. There is clear evidence of differences among bulls in cleavage rates and embryo yields (Lu et al., 1987). Therefore, it is important to find an acceptable bull to produce the highest percentage of blastocysts. Especially when experimenting on other factors which might improve blastocyst yield. From the results on sperm motility and morphology for bull FR1792, this bull should be acceptable for IVF. Shi et al (1990) showed a threefold variation in embryo yield ( $10.6 \%$ to $30.5 \%$ ) depending on which bull was used in IVF. To limit variation when doing experiments on blastocyst production rates, the same bull should be used for all IVF procedures.

Also, the heparin concentration for optimum capacitation and fertilizing ability differs for each bull. The present results show a two-fold variation ( $10 \%$ vs $18 \%$ ) over the three different heparin levels used for bull FR1792. The heparin concentration of $10 \mu \mathrm{g} / \mathrm{ml}$ found to be optimum (giving the highest fertilization percentage of $71 \%$ and the highest blastocyst production percentage of $18 \%$ ) in the present study is consistent with other results where this level was found to produce optimal fertilization rates and blastocyst production rates (Parrish et al., 1986; Niwa and Ohgoda, 1988). Heparin levels greater than $20 \mu \mathrm{g} / \mathrm{ml}$ were not tested because high heparin doses increase the risk of a high incidence of polyspermy (Gordon, 1994). Gordon (1994) suggests a polyspermy incidence of 8 to $10 \%$ when using heparin to capacitate spermatozoa. The percentage of oocytes exhibiting polyspermy was under $10 \%$ for all three heparin treatments in this study.

\subsubsection{ITS added to maturation medium}

The finding that supplementation of the maturation medium with unfiltered ITS increased the number of oocytes which matured (Experiment 2) agrees with Shamsuddin et al. (1994). They showed that a tissue culture medium supplemented with bovine serum albumin, insulin, selenium and transferrin supported development of in vitro matured and in vitro fertilized oocytes. The maturation rates 
obtained between the three different levels of ITS was non significant, suggesting that there is a range between which ITS can be effective $(3.3 \mu \mathrm{g} / \mathrm{ml}-10 \mu \mathrm{g} / \mathrm{ml})$. At some point though, the level will be too low to induce an effect or too high where levels could become toxic as both selenium and transferrin are toxic elements at high levels. The use of ITS did not allow the individual effects of insulin, selenium and transferrin to be separated. This may be necessary, as Poff et al. (1988) found that transferrin or selenium, without insulin inhibited the stimulation of progesterone synthesis by LH. It is also important to allow the in vitro study to proceed to the blastocyst stage, as Herrler et al. (1992) observed that addition of ITS to the maturation and culture media can increase the number of morulae and blastocysts. In Experiment 3 the addition of the components of ITS were evaluated separately and evaluations were followed to the blastocyst stage. The concentrations decided on were $10 \mu \mathrm{g} / \mathrm{ml}$ for insulin, $10 \mathrm{ng} / \mathrm{ml}$ for selenium and $10 \mu \mathrm{g} / \mathrm{ml}$ for transferrin. These levels had previously been shown to improve maturation rates and showed no signs of becoming toxic (Bowles, 1996).

\subsubsection{Insulin, selenium or transferrin added individually or in combinations to maturation, fertilization or culture media}

Experiment 3 was based on the results from Experiment 2. In Experiment 3a, where the different substances are added to maturation medium, insulin significantly $(\mathrm{P}<0.05)$ increased the maturation rate, but not when in combination with selenium or transferrin. However, insulin $(10 \mu \mathrm{g} / \mathrm{ml})$ did not improve fertilization rates or blastocyst production rates. This result agrees with Zhang et al. (1991) who showed that when M199 was supplemented with insulin cumulus expansion scores and the level of maturation were improved. They also observed that the yield of morulae and development of blastocysts were not affected. In contrast, Matsui et al. (1995) added insulin at $10 \mu \mathrm{g} / \mathrm{ml}$ to M199 containing $10 \% \mathrm{FCS}$ and noted that maturation rates of oocytes were not affected. Feng et al. (1988) also showed that insulin (at $1 \mu \mathrm{g} / \mathrm{ml}$ ) had no effect on stimulating oocyte maturation compared to their control. This is in agreement with Roy and Greenwald (1989) who suggested that insulin alone was insufficient. Tornesi et al. (1995) added insulin plus transferrin to maturation media and also found no significant beneficial effect on maturation rates. The present results suggest that insulin works alone to improve the maturation rate. 
Transferrin alone or when in combination with insulin or selenium caused a significant $(\mathrm{P}<0.01)$ decrease in either the fertilization rates or the blastocyst production rates or both, even though maturation rates were increased. This suggests that by adding transferrin the oocyte is over-stimulated and development after maturation is impeded. The combination of insulin, selenium and transferrin increased maturation rates, but the differences were not significant. Although the fertilization rates were significantly $(\mathrm{P}<0.01)$ improved there was no improvement in the blastocyst production rate. This treatment is beneficial for the maturation and fertilization stages, but at the culture stage something more is needed, or the oocyte needs more stimulation at the maturation level. When transferrin is removed from the combination (insulin + selenium treatment) blastocyst formation is increased. As with previous treatments with transferrin it appears that this element has a toxic effect on the maturing oocyte, which manifests itself later and affects blastocyst production rates. This effect of transferrin is very noticeable when it is in combination with selenium. The polyspermy rates were significantly $(\mathrm{P}<0.01)$ increased, which suggests that transferrin competes with selenium as both these elements have anti-oxidant properties.

Selenium alone significantly $(\mathrm{P}<0.01)$ increased maturation, fertilization, cleavage and blastocyst production rates. Also, polyspermy rates were significantly $(\mathrm{P}<0.05)$ decreased. Selenium in combination with insulin significantly $(\mathrm{P}<0.01)$ improved cleavage rates and blastocyst production rates. This suggests that selenium is beneficial in preparing the oocyte for later development and could be working through its anti-oxidant actions by scavenging super-oxide radicals and sufficiently preventing membrane damage. It appears that addition of selenium $(10 \mathrm{ng} / \mathrm{ml})$ to the maturation medium would give improved maturation ( $80.4 \%$ vs $61.8 \%$ ), fertilization $(68.0 \%$ vs $58.4 \%$ ) and blastocyst yields $(24.6 \%$ vs $11.5 \%)$.

In Experiment 3b, where fertilization medium was supplemented, the addition of insulin and transferrin individually, insulin plus selenium and insulin plus transferrin to the fertilization medium adversely affected IVF. The fertilization rates were significantly $(\mathrm{P}<0.01)$ decreased and the polyspermy rates were increased. This suggests that spermatozoa are very sensitive to unnatural elements, perhaps, not usually found in the bull ejaculate or in the female reproductive tract. Another explanation is that by addition of these factors, the oocyte is affected at a, perhaps, very sensitive and crucial stage. The blocks which prevent polyspermy might be affected and once polyspermy has occurred the embryo may 
not survive many cleavage divisions. Addition of selenium in combination with transferrin or insulin plus transferrin had no significant effect on fertilization rates which agrees with Eppig et al (1986). They added ITS to IVF and found no significant improvement in fertilization rates. However, selenium alone $(10 \mathrm{ng} / \mathrm{ml})$ did significantly $(\mathrm{P}<0.01)$ improve fertilization percentages. This was expected after the reports of improved fertility in vivo after selenium ingestion (MacPherson et al., 1993; El-Masry et al., 1994). Selenium deficiencies have been shown to impair sperm motility (Slaweta et al., 1988). Thus, by addition to the medium, selenium may be providing an essential element to sperm mitochondria and thereby improve motility and fertilization rates. No treatments had a significant effect on blastocyst production rates. The improved fertilization percentages, when selenium was added, are most probably due to the action of selenium on the spermatozoa and not on the oocytes and so development of the embryo cannot be sustained in the culture medium. Fertilization seems to be a very sensitive stage in in vitro culture that is best left as simple as possible. From the present results it is suggested that none of the above treatments should be added to IVF as no benefit is observed in the blastocyst production rate.

In Experiment 3c, where additions to the culture medium was evaluated, addition of selenium plus transferrin, insulin plus transferrin, insulin plus selenium or selenium alone, to the culture medium, did not significantly affect blastocyst production rates (Table 7). These treatments did, however, significantly improve the cleavage rates and this suggests that development of the early embryo is advantaged. This could be because of differences in needs of the early embryo compared to the late embryo, especially with regard to glucose utilization. Insulin significantly increased cleavage rates, but decreased blastocyst production rates which could be because the post-compacted embryo is highly sensitive to insulin (Harvey and Kaye, 1988). Harvey and Kaye (1988) showed a stage-specific binding by insulin, which could be related to embryonic metabolism and the switch from lactate to glucose utilization. Kimura and Totsukawa (1995) observed that the percentage of embryos developing to the 8-cell stage was significantly increased by addition of $10 \mu \mathrm{g} / \mathrm{ml}$ insulin to the culture medium, but development to the morula stage and blastocyst stage were not significantly increased. Present results agree with these findings (Table 7). Matsui et al, (1995) added $5 \mu \mathrm{g} / \mathrm{ml}$ insulin to the culture medium and the percentage of embryos reaching the morula stage was not affected by addition of insulin alone, but was significantly increased by addition of insulin and amino acids. They found a significant increase in the number of cells in blastocysts, suggesting that insulin can improve embryonic development by stimulating amino acid transport and/or glucose uptake. This suggests that a higher level of amino acids 
and/or glucose is needed in the culture medium to realise improvements to blastocyst yield by addition of insulin.

Transferrin and insulin plus selenium plus transferrin significantly improved the blastocyst yield. Natsuyama et al. (1993) also showed the prominent growth-promoting activity of transferrin when added to IVC media and that the growth promoting effect was due to anti-oxidant action or to the removal of metal ions such as $\mathrm{Fe}^{3+}$. Iron is the fourth most abundant element in the earths crust (Neve and Favier, 1988) and could be present in small amounts in the water used as the base for all media preparations. Due to normal cell respiration the reduction of oxygen does occur and forms superoxide radicals which are harmful in large, uncontrolled amounts. In the presence of free radicals, iron is reduced to the ferrous state and together these radicals and iron form a very harmful hydroxy radical via the Fenton reaction and this damages tissues and biological molecules as badly as radiation can (Neve and Favier, 1988). An antioxidant like selenium can prevent harmful radicals occurring by scavenging all excess by-products, but when iron is present this cannot be completely controlled by selenium. This is where transferrin is beneficial as iron can be removed from the media before breakdown to its ferrous state. In addition, iron will then safely exist within the cell where it can support the synthesis of iron containing proteins (Neve and Favier, 1988). This would explain why transferrin either alone or when in combination with insulin and selenium improves blastocyst production rates. Shamsuddin et al. (1994) added BSA and ITS $(5 \mu \mathrm{g} / \mathrm{ml})$ to cultured IVM/IVF oocytes and found that the percentage of embryos showing cleavage and blastocyst production did not differ from the control, but the blastocysts had a better viability and post-thaw survivability. The present results show that transferrin $(10 \mu \mathrm{g} / \mathrm{ml})$ also improved the percentage of blastocysts which hatched (21.9\% vs 14.2\%). Flechon and Renard (1978) believe that the number of blastocysts hatching is a indicator of the adequacy of the culture conditions. Viability of the blastocyst is important as an end point when trying to produce calves and it seems that addition of transferrin to the culture medium would be most beneficial to improving blastocyst yields and viability in the IVC system. 


\subsubsection{Future work}

It has been shown that transferrin and insulin plus transferrin plus selenium significantly $(\mathrm{P}<0.05)$ increase blastocyst yield, but the effect on the number of pregnancies is not known. Future work should involve transferring the viable embryos to recipient females to judge embryo viability beyond the hatching stage.

Some treatments improved early development, but not late development and others improved late development. This suggests that static culture conditions are not ideal. Instead of just one medium being used for seven days in culture it should be changed at say the 8-cell stage (for example) where a known embryo transition occurs. Then, treatments that significantly increased cleavage rates (insulin or selenium) could be added to the early embryo stage and treatments that significantly increased blastocyst production rates (transferrin or insulin plus selenium plus transferrin) could be added to the late embryo stage.

It might also be beneficial to select presumptive zygotes after fertilization before further culture, like the selection of oocytes before maturation. Hawk and Wall (1994a) suggest selection of the presumptive zygote based on quality of cytoplasm at 48 hours after exposure to sperm could increase the proportion of zygotes that would develop to the expanded blastocyst stage. They determined which ova were cleaved and those that were uncleaved were removed from the culture medium. 


\section{IMPLICATIONS}

Effective techniques for the large scale laboratory production of cattle embryos will provide embryos which can be transferred non-surgically by way of a technique little different from that used in artificial insemination and that can be utilized in normal farming practice. It is cattle embryo production linked to cattle embryo transfer technology that will allow advantage to be taken of the considerable advances that are currently taking place in development of IVF techniques.

The application of IVF technology as a means of upgrading the quality of cattle in developing countries is one possibility worth exploring. Bos taurus $\mathrm{x}$ Bos indicus crossbreds have merit in combining the qualities of productivity with the ability to withstand the rigours of the tropical and subtropical environment. Under conventional animal breeding schemes, however, such crossbreds cannot be sustained beyond the first generation. It is desirable to maintain the milking cow population at $50 \%$ Bos taurus : 50\% Bos indicus to exploit heterosis, and such a population cannot be replaced under existing breeding programmes (Gordon, 1994). The use of IVF technology to produce crossbred embryos derived from European dairy cattle (e.g. Jersey) and native African bulls (e.g. Nguni) may be one solution to the problem. It would be possible to use oocytes from ovaries from Jersey cattle either via ultrasound-guided retrieval or from abattoir collection and to fertilize the oocytes with frozen/thawed Nguni semen. The embryos could then be used in any fertile cow by way of direct non-surgical transfers by suitably trained personnel. Transferred embryos adapt to new environments as they receive passive immunity to local diseases from their surrogate mothers.

One possibility of making IVF embryo production technology available to stud cattle farmers is by obtaining oocytes from clinically infertile, but valuable, cattle or by collecting oocytes from the ovaries of a valuable cow after its death and then producing embryos by IVF and IVC. Recent advances in IVF technology make it possible to recover oocytes from the live cow using ultrasonic equipment (ultrasound-guided aspiration). Collections can be done twice-weekly for several months and there is no need for superovulation. One can collect from prepubertal heifers, postpartum anoestrous cows and animals in their first trimester of pregnancy. There may even be the possibility of using semen sexed by flow cytometry (Cran et al., 1993; 1994) in the planned production of bulls or heifers. 
There is increasing interest in the establishment of programmes for the preservation of livestock breeds that may be in danger of extinction, in both developed and developing countries. Intensification of agriculture in developed countries has led to greater reliance on a small number of breeds, with consequent neglect of the remainder. In developing countries, the greatest threats to genetic diversity appear to be indiscriminate crossbreeding of indigenous breeds with exotic breeds, in aiming for greater production (Gordon, 1994). Future developments in IVF technology, such as methods for recovering much larger numbers of oocytes from ovaries and effective cloning techniques, are likely to be of great value in the preservation of embryos from endangered species. This technology described for the cow can, with certain modifications, be employed in other farm animals as well as wildlife. 


\section{REFERENCES}

Aoyagi, Y., Fujii, K., Irazumi, Y., Furudate, M., Fukui, Y. and Ono, H. (1988) Effects of two treatments on semen from different bulls on in vitro fertilization results of bovine oocytes. Theriogenology 30:973-985.

Arechiga, C.F., Ortíz, O. and Hansen, P.J. (1994) Effect of prepartum injection of vitamin E and selenium on postpartum reproductive function of dairy cattle. Theriogenology 40:1251-1258.

Austin, C.R. and Short, R.V. (1982) Germ cells and fertilization. In: Reproduction in mammals Vol. 1 (C.R. Austin and R.V. Short, eds), pp.5-23.

Austin, C.R. and Short, R.V. (1984) Hormonal control of reproduction. In: Reproduction in mammals Vol. 3 (C.R. Austin and R.V. Short, eds), pp.1-10.

Austin, C.R. and Short, R.V. (1987) Embryonic and fetal development. In: Reproduction in mammals Vol.2 (C.R. Austin and R.V. Short, eds), pp.18-21.

Barnes, F. L. and Eyestone, W. H. (1990) Early cleavage and the maternal zygotic transition in bovine embryos. Theriogenology 33:141 - 152.

Bowles, C.M. (1996) Attempts to improve the yield of bovine blastocysts by incorporating insulin, selenium and transferrin in the in vitro system. Thesis MscAgric. University of Natal, Pietermaritzburg.

Brackett, B.G. and Zuelke, K.A. (1993) Analysis of factors involved in the in vitro production of bovine embryos. Theriogenology 39:43-64.

Brown, D.G. and Burk, R.F. (1973) Selenium retention in tissues and sperm of rats fed a torula yeast diet. J. Nutr. 102:102. 
Buchanan-Smith, J.G., Nelson, E.C., Osburn, B.I., Wells, M.E. and Tillman, A.D. (1969) Effects of vitamin $\mathrm{E}$ and selenium deficiencies in sheep fed a purified diet during growth and reproduction. J. Anim. Sci. 29:808.

Buck, G.L., Schmitz, J.A. and Swanson L.V. (1980a) Incorporation of Se into endocrine glands and reproductive tissues of the prepartum ewe and fetus. In: Selenium in biology and medicine (J.E. Spallholz, J.L. Martin and H.E. Ganter, eds.), pp 514.

Buck, E.L., Tripp, M.J., Schmitz, J.A. and Swanson, L.V. (1980b) Preferential incorporation of ${ }^{75} \mathrm{Se}$ into reproductive and placental tissues of the pregnant pigmy goat and its fetus. J. Anim.Sci. 51:264(Abstr.).

Butler, J.E. and Williams, J.E. (1990) Effect of insulin on glucose uptake by murine embryos in low glucose medium. Theriogenology 33:203(Abstr.).

Caubo, B., DeVinna, R.S. and Tonetta, S.A. (1989) Regulation of steroidogenesis in cultured porcine theca cells by growth factors. Endocrinology 125:321-326.

Chian, R.C., Nakahara, H., Niwa, K. and Funahashi, H. (1992) Fertilization and early cleavage in vitro of aging bovine oocytes after maturation in culture. Theriogenology 37:666-672.

Cran, D.G., Johnson, L.A., Miller, N.G., Cochrane, D. and Polge, C. (1993) Production of bovine calves following separation of $\mathrm{X}$ and $\mathrm{Y}$ chromosome bearing sperm and in vitro fertilization. Vet Record. 132:40-41.

Cran, D.G., Cochrane, D.J., Johnson, L.A., Wei, H., Lu, K.H. and Polge, C. (1994) Seperation of X and $\mathrm{Y}$ chromosome bearing bovine sperm by flow cytometry for use in IVF. Theriogenology 41:183.

Eberhardt, D.M., Henricks, D.M., Dickey, J.F. and Diehl, J.R. (1994) Oviductal fluid and growth factors failed to enhance development of porcine embryos. Theriogenology 41:1163-1172. 
Elhassan, Y.M. and Wright,Jr., R.W. (1995) The effect of selenium and vitamin E addition on cleavage rate of IVM/IVF bovine oocytes. Theriogenology 43:206(Abstr.).

El-Masry, K.A., Nasr, A.S. and Kamal, T.H. (1994) Influences of season and dietary supplementation with selenium and vitamin $\mathrm{E}$ or zinc on some blood constituents and semen quality of New Zealand White rabbit males. World Rabbit Science 2:3, 79 - 86(Abstr.).

Eppig, J. J. and Allen, C. S. (1986) Culture systems for mammalian oocyte development: Progress and prospects. Theriogenology 25:97 - 106.

Feng, P., Catt, K. and Knecht, M. (1988) Transforming growth factor $-\beta$ stimulates meiotic maturation of the rat oocyte. Endocrinology 122:181 - 186.

Flechon, J. and Renard, J. P. (1978) A scanning electron microscope study of the hatching of bovine blastocysts in vitro. J. Reprod. Fert. 53:9 - 12.

Gordon, I. (1994) In: Laboratory production of cattle embryos, 1st ed. (I. Gordon, ed). University Press, Cambridge.

Greve, T., Bousquet, D., King, W.A and Betteridge, K.S. (1984) In vitro fertilization and cleavage of in vitro matured bovine oocytes. Theriogenology 22:151-165.

Harrison, J.H., Hancock, D.D. and Conrad, R. (1984a) Selenium content and glutathione peroxidase activity in tissues of the dairy cow after short term feeding. J. Dairy Sci. 67:2464 - 2470.

Harrison, J.H., Hancock, D.D. and Conrad, R. (1984b) Vitamin E and selenium for reproduction of the dairy cow. J. Dairy Sci. 67:123-132.

Harvey, M.B. and Kaye, P.L. (1988) Insulin stimulates protein synthesis in compacted mouse embryos. Endocrinology 122:1182-1184. 
Hawk, H.W. and Wall, R.J. (1994a) Improved yields of bovine blastocysts from in vitro produced oocytes. I. Selection of oocytes and zygotes. Theriogenology 41:1571 - 1583.

Hawk, H.W. and Wall, R.J. (1994b) Improved yields of bovine blastocysts from in vitro produced oocytes. II. Media and co-culture cells. Theriogenology 41:1585-1594.

Herrler, A., Lucas-Hahn, A. and Niemann, H. (1992) Effects of insulin-like growth factor I on in vitro production of bovine embryos. Theriogenology 37:1213-1224.

Heyner, S., Shah, N., Smith, R.M., Watson, A.J. and Schultz, G.A. (1993) The role of growth factors in embryo production. Theriogenology 39:151-161.

Hill, D.J. (1989) Growth factors and their cellular actions. J. Reprod. Fert. 85:723-734.

Iritani, A. And Niwa, K. (1977) Capacitation of bull spermatozoa and fertilization in vitro of cattle follicular oocytes matured in culture. J. Reprod. Fert. 50:119-121.

Jewgenow, K. and Pitra, C. (1993) Hormone controlled culture of secondary follicles of domestic cats. Theriogenology 39:527-535.

Jiang, H. S., Wang, W. L., Lu, K. H. and Gordon, I. (1990) Effects of PMSG, insulin, osmolality and oestrous cow serum on development of IVF early bovine embryos cultured on granulosa cell monolayers. Theriogenology 33:258 (Abstr.).

Johnson, M. and Everitt, B. (1980) Essential Reproduction (M. Johnson and B. Everitt, eds), pp.3467 and pp.108-123. Blackwell, Oxford.

Julien, W.E., Conrad, H.R., Jones, J.E. and Moxon, A.L. (1976) Selenium and vitamin E and incidence of retained placenta in parturient dairy cows. J. Dairy. Sci. 59:1954. 
Kane, M.T., Carney, E.W. and Ellington, J.E. (1992) The role of nutrients, peptide growth factors and co-culture cells in development of preimplantation embryos in vitro. Theriogenology 38:297 - 313

Kimura, F. and Totsukawa, K. (1995) Effects of insulin on development of embryos derived from in vitro fertilization. J. of Agric. For. Soc. 52:13 - 16 (Abstr.).

Kobayashi, K., Yamashita, S. and Hoshi, H. (1994) Influence of epidermal growth factor and transforming growth factor- $\alpha$ on in vitro maturation of cumulus cell enclosed bovine oocytes in a defined medium. J. Reprod. Fert. 100:439-446.

Lamb, C.A, Bentley, D.G. and Beattle, J.M. (1958) Proceedings of the conference held at the Ohio Agricultural Experiment Station. In: Trace elements (C.A. Lamb, D.G. Bentley and J.M. Beattle, eds), pp. 175 and pp 365.

Lee, C.H. and Ax, R.L. (1984) Concentrations and composition of glycosaminoglycans in the female bovine reproductive tract. J. Dairy Sci.67:2006-2009.

Leibfried, M.L. and Bavister, B.D. (1982) Effects of epinephrine and hypotaurine on in vitro fertilization in the golden hamster. J. Reprod. Fert. 66:87-93.

Liu, Z. and Foote, R.H. (1995) Effects of $\mathrm{O}_{2}$ concentrations and superoxide dismutase on the development of IVM/IVF bovine embryos in KSOM with $2.5 \mathrm{mM}$ Hepes. Theriogenology 43:268(Abstr.).

Lu, K.H., Gordon, I., Gallagher, M. and McGovern, H. (1987) Pregnancy established in cattle by transfer of embryos derived from in vitro fertilization of follicular oocytes matured in vitro. Veterinary Record 121:159-206.

MacPherson, A., Fisher, G. and Paterso, J.E. (1993) Effect of cobalt deficiency on the immune function of ruminants. In: Trace elements in man and animals (L. Hurley, C. Keen andR. Rucher, eds). 
Mastroianni, L. and Biggers, J. (1981) Fertilization and embryonic development In Vitro (L. Mastroianni and J. Biggers, eds). Plenum, New York.

Matsui, M., Takahashi, Y., Hishinuma, M. and Kanagawa, H. (1995) Stimulatory effects of insulin on the development of bovine embryos fertilized in vitro. J. Vet. Med. Sci. 57:2, 331 - 336 (Abstr.).

McClure, T.J. (1994) Nutritional and metabolic infertility in the cow (T.J. McClure, ed).

Nasr-Esfahani, M.H. and Johnson, M.H. (1992) How does transferrin overcome the in vitro block to development of the mouse preimplantation embryo? J. Reprod. Fert. 96:41-48.

Natsuyama, S., Noda, Y., Narimoto, K. and Mori, T. (1993) Role of protein supplements in the culture of mouse embryos. Theriogenology 40:149-157.

Neve, J. and Favier, A. (1988) Proceedings of the second international congress on trace elements in medicine and biology. In: Selenium in medicine and biology (J. Neve and A. Favier, eds), pp 104.

Niwa, K. And Ohgoda, O. (1988) Synergistic effect of caffeine and heparin on in vitro fertilization of cattle oocytes matured in culture. Theriogenology 30:733-741.

Nothling, J.O. and Arndt, E. (1996) Short coarse: Freezing of bull semen and evaluation of frozen bull semen. Taurus and University of Pretoria.

Oliver, J.E., Aitman, T.J., Powell, J.F., Wilson, A.W. and Clayton, R.N. (1989) Insulin-like growth factor I gene expression in the rat ovary is confined to the granulosa cells of developing follicles. Endocrinology 124:2671-2679.

Olson, S.E. and Seidel,Jr., G.E. (1995) Vitamin E improves development of bovine embryos produced in vitro. Theriogenology 43:289(Abstr.). 
Paria, B.C. and Dey, S.K. (1990) Preimplantation embryo development in vitro: Cooperative interactions among embryos and role of growth factors. Proc. Natl. Acad. Sci. USA 87:47564760.

Parrish, J.J., Susko-Parrish, J.L., Liebfried-Rutledge, M.L., Critser, E.S., Eyestone, W.H. and First, N.L. (1986) Bovine in vitro fertilization with frozen-thawed semen. Theriogenology 25:591600.

Peluso, J. and Hirschel, M. (1987) Role of gonadotropins and insulin in controlling steroidogenesis and growth of antral follicles in perifusion culture. Theriogenology 28:503-512.

Poff,J.P., Fairchild, D.L. and Condon, W.A. (1988) Effects of antibiotics and medium supplements on steroidogenesis in cultured cow luteal cells. J. Reprod. Fert. 82:135-143.

Prasad, A.S. (1978) Trace elements and iron in human metabolism (A.S. Prasad, ed). Wiley, Sussex.

Rexroad,Jr., C.E. and Powell, A.M. (1988) Co-culture of ovine ova with oviductal cells in Medium 199. J. Anim. Sci. 66:947-953.

Rieger, D. (1992) Relationships between energy metabolism and development of early mammalian embryos. Theriogenology 37:75-93.

Rotruck, J.T., Pope, A.L., Ganther, H.E., Hafeman, D.G. and Hoekstra, W.G. (1972) Selenium: Biochemical role as a component of glutathione peroxidase. Science 179:588-590.

Roy, K. and Greenwald, G.S. (1989) Hormonal requirements for the growth and differentiation of hamster preantral follicles in long term culture. J. Reprod. Fert. 87:103-111

Sanbuissho, A. and Threlfall, W.R. (1990) The influence of serum and gonadotropins on in vitro maturation and fertilization of bovine oocytes. Theriogenology 34:341-348. 
Sanchez, L., Lujan, L., Oria, R., Castillo, H., Perez, D., Ena, J.M. and Calvo, M. (1992) Nutrition, feeding and calves: Synthesis of lactoferrin and transport of transferrin in the lactating mammary gland of sheep. J. Dairy Sci. 75:1257-1262.

Segerson,Jr., E.C., Murray, F.A., Moxon, A.L., Reidman, D.R. and Conrad, H.R. (1977) Selenium/vitamin E: Role in fertilization of bovine ova. J. Dairy Sci. 60:1001-1005.

Segerson, E.C. and Ganapathy, S.N. (1981) Fertilization of ova in selenium/vitamin E treated ewes maintained on two planes of nutrition. J. Anim. Sci. 51:386-394.

Shamsuddin, M., Larsson, B., Gutafsson, H. and Rodriguez-Martinez, H. (1994) A serum free, cell free culture system for development of bovine one-cell embryos up to blastocyst stage with improved viability. Theriogenology 41:1033-1043.

Shi, D.S., Lu, L.H. and Gordon, I. (1990) Effects of bulls on fertilization of bovine oocytes and their subsequent development in vitro. Theriogenology 33:324.

Shi, D.S., Lu, K.H., Gordon, I. And Polge, C. (1991) Variation in cleavage and embryonic development of bovine oocytes in vitro fertilized with different bull ejaculates. Theriogenology 35:271.

Slaweta, R., Wasowicz, W. and Laskowska, T. (1988) Selenium content, glutathione peroxidase activity and lipid peroxide level in fresh bull semen and its relationship to motility of spermatozoa after freeze-thawing. J. Vet. Med. 35: 6, 455-460(Abstr.).

Staats, D.A., Lohr, D.P. and Colby, H.D. (1988) Effects of tocopherol depletion on the regional differences in adrenal microsomal lipid peroxidation and steroid metabolism. Endocrinology 123:975-980.

Stubbings, R.B., Liptrap, R.M., Betteridge, K.J., Walton, J.S., Armstrong, D.T. and Basrur, P.K. (1990) Requirements for bovine oocyte maturation in vitro. Reprod. Dom. Anim. 25:158-166. 
Susko-Parrish, J.L., Wheeler, M.B., Ax, R.L., First, N.L. and Parrish, J.J. (1990) The effect of penicillamine, hypotaurine, epinephrine and sodium metabisulfite on bovine in vitro fertilization. Theriogenology 33:333.

Sutton, R., Nancarrow, C.D., Wallace, A.L.C. and Rigby, N.W. (1984) Identification of an oestrus associated glycoprotein in oviducal fluid of the sheep. J. Reprod. Fert. 72:415-422.

Takagi, Y., Mori, K., Tomizawa, M., Takahashi, T., Sugawara, S. and Masaki, J. (1991) Development of bovine oocytes matured, fertilized and cultured in a serum free, chemically defined medium. Theriogenology 35:1197-1207.

Tornesi, M.B., Salamone, D. and Archer, J. (1995) In vitro maturation of bovine oocytes in serum free medium. Theriogenology 43:339(Abstr.).

Trowbridge, I.S. and Lopez, F. (1982) Monoclonal antibody to transferrin receptor blocks transferrin binding and inhibits human tumor cell growth in vitro. Proc. Nat. Acad. Sci. USA 79:1175-1179.

Wood, S.A. and Kaye, P.L. (1989) Effects of epidermal growth factor on preimplantation mouse embryos. J. Reprod. Fert. 85:575-582.

Yang, Y.B. and Lu, K. H. (1990) The influence of bovine oocyte type on in vitro fertilization and subsequent development in vitro. Theriogenology 33:335 (Abstr.).

Zhang, L., Blakewood, E. G., Denniston, R. S. and Godke, R. A. (1991) The effect of insulin on maturation and development of in vitro fertilized bovine oocytes. Theriogenology 35:301 (Abstr.).

Zhang, X., Kidder, G.M., Watson, A.J., Schultz, G.A. and Armstrong, D.T. (1994) Possible roles of insulin and insulin-like growth factors in rat preimplantation development: investigation of gene expression by reverse transcription-polymerase chain reaction. J. Reprod. Fert. 100:375-380. 


\section{APPENDIX 1}

\section{Heparin, ITS and Insulin, Selenium and Transferrin stock solutions.}

\section{Heparin}

- A stock solution of $1 \mathrm{mg}$ heparin/ml (Sigma Chemical Co,, U.S.A.) was made up in physiological saline and filtered through a $0.22 \mu \mathrm{m}$ acetate filter (Micron Separations, Inc.).

- $5 \mu 1,10 \mu \mathrm{l}$ or $20 \mu \mathrm{l}$ of this stock was then added to $95 \mu 1,90 \mu \mathrm{l}$ or $80 \mu$ fertilization medium which yielded a final working stock solution of $5 \mu \mathrm{g}, 10 \mu \mathrm{g}$ or $20 \mu \mathrm{g}$ heparin $/ \mathrm{ml}$.

\section{ITS}

- To prepare a stock solution of $1 \mathrm{mg} / \mathrm{ml}$ insulin, $1 \mathrm{mg} / \mathrm{ml}$ transferrin and $1 \mu \mathrm{g} / \mathrm{ml}$ selenium; dissolve Insulin-Transferrin-Sodium selenite media supplement (Sigma Chemical Co., U.S.A.) into $50 \mathrm{ml}$ sterile water.

- $16,5 \mu \mathrm{l}, 25 \mu \mathrm{l}$ or $50 \mu \mathrm{l}$ of this stock added to $5 \mathrm{ml}$ maturation medium gives a final concentration of $20 \mathrm{nM}, 29 \mathrm{nM}$ or $58 \mathrm{nM}$ ITS respectively.

- Stock is snap frozen in liquid nitrogen in working aliquots, avoid repeated freeze/thaw.

\section{Insulin}

- To prepare $10 \mathrm{mg} / \mathrm{ml}$ stock solution add $10 \mathrm{ml}$ double distilled water and $100 \mu 1$ glacial acetic acid to $100 \mathrm{mg}$ Insulin from bovine pancreas (Sigma Chemical Co., U.S.A.).

- To get a final concentration of $10 \mu \mathrm{g} / \mathrm{ml}$ add $10 \mu \mathrm{l}$ of stock to $10 \mathrm{ml}$ culture media

- Working aliquots snap frozen in liquid nitrogen, solution stable at $2-6^{\circ} \mathrm{C}$ for 30 days.

\section{Sodium Selenite}

- To prepare $20 \mu \mathrm{g} / \mathrm{ml}$ stock solution add $50 \mathrm{ml}$ sterile saline to $1 \mathrm{mg}$ Sodium Selenite (Riedel-deHaen, $\mathrm{Na}_{2} \mathrm{SeO}_{3}$ ).

- To get a final concentration of $10 \mathrm{ng} / \mathrm{ml}$ add $5 \mu$ of stock to $10 \mathrm{ml}$ culture media.

- Working aliquots are snap frozen, avoid repeat freeze/thaw. 


\section{APPENDIX 1 contd.}

\section{Transferrin}

- To prepare $1 \mathrm{mg} / \mathrm{ml}$ stock solution add $10 \mathrm{ml}$ sterile saline to $10 \mathrm{mg}$ Transferrin (Sigma Chemical Co., U.S.A.).

- To get final concentration of $10 \mu \mathrm{g} / \mathrm{ml}$ add $100 \mu \mathrm{l}$ of stock to $10 \mathrm{ml}$ culture media.

- Working aliquots are snap frozen, solution is stable at $2-6^{\circ} \mathrm{C}$ for 30 days.

Stock solutions and culture media for in vitro maturation, fertilization and culture.

(Recipes for media are from the Laboratory Manual, Dept. Animal Science, University of Natal, Pietermaritzburg (1996)).

All media were filter sterilised through a $0.22 \mu \mathrm{m}$ acetate filter (Micron Separations Inc.) and equilibriated for a minimum of 2 hours at $38.5^{\circ} \mathrm{C}$ and $5 \% \mathrm{CO}_{2}$ before use.

\section{Physiological saline}

$9.21 \mathrm{~g} \mathrm{NaCl}$ (Sigma Chemical Co.)/ litre of double distilled water plus $500 \mu \mathrm{l}$ gentamycin (Sigma Chemical Co.)

M199 Hepes wash medium

\begin{tabular}{|c|c|c|c|}
\hline Reagent & Source & Amount & Final concentration \\
\hline M199 Hepes & Sigma $\quad M-2520$ & $99 \mathrm{ml}$ & $\mathrm{n} / \mathrm{a}$ \\
\hline BSA fraction V & Sigma A - 8022 & $100 \mathrm{mg}$ & $1 \mathrm{mg} / \mathrm{ml}$ \\
\hline Pyruvate stock & Sigma $P-5280$ & $1 \mathrm{ml}$ & $0.2 \mathrm{mM}$ \\
\hline Gentamycin stock & Sigma $G-3632$ & $50 \mu \mathrm{l}$ & $25 \mu \mathrm{g} / \mathrm{ml}$ \\
\hline Heparin 10X stock & Sigma H - 3393 & $50 \mu l$ & $5 \mu \mathrm{g} / \mathrm{ml}$ \\
\hline
\end{tabular}


APPENDIX 1 contd.

TCM199 Maturation medium

\begin{tabular}{llll}
\hline Reagent & Source & Amount & Final concentration \\
\hline TCM 199 & Sigma M - 5017 & $9 \mathrm{ml}$ & $\mathrm{n} / \mathrm{a}$ \\
\hline FCS (heat-inactivated) & Highveld Biological & $1 \mathrm{ml}$ & $10 \%$ \\
\hline Pyruvate stock & Sigma P - 5280 & $100 \mu \mathrm{l}$ & $0.2 \mathrm{mM}$ \\
\hline LH stock & Sigma L - 9773 & $25 \mu \mathrm{l}$ & $2.5 \mu \mathrm{g} / \mathrm{ml}$ \\
\hline FSH-p stock & Sigma F - 8001 & $50 \mu \mathrm{l}$ & $20 \mu \mathrm{g} / \mathrm{ml}$ \\
\hline$E_{2}$ stock & Sigma E - 8875 & $1 \mu \mathrm{l}$ & $1 \mu \mathrm{g} / \mathrm{ml}$ \\
\hline Gentamycin stock & Sigma G - 3632 & $5 \mu \mathrm{l}$ & $25 \mu \mathrm{g} / \mathrm{ml}$ \\
\hline
\end{tabular}

$T L$ - stock

\begin{tabular}{llll}
\hline Reagent & Sigma Cat. No. & mg/100ml & Final concentration (mM) \\
\hline $\mathrm{NaCl}$ & $\mathrm{S}-5886$ & 584 & 100 \\
\hline $\mathrm{KCl}$ & $\mathrm{P}-5405$ & 23 & 3.1 \\
\hline $\mathrm{NaHCO}$ & $\mathrm{S}-5761$ & 210 & 25 \\
\hline $\mathrm{NaH}_{2} \mathrm{PO}_{4} \mathrm{H}_{2} \mathrm{O}$ & $\mathrm{S}-9638$ & 4 & 0.29 \\
\hline $\mathrm{Hepes}$ & $\mathrm{H}-3375$ & 238 & 10 \\
\hline Phenol red & $\mathrm{P}-5530$ & 1 & $1 \mathrm{mg} / 100 \mathrm{ml}$ \\
\hline $\mathrm{Na}$ lactate & $\mathrm{L}-4263$ & $0.386 \mathrm{ml}$ & 21.6 \\
\hline $\mathrm{CaCl}_{2} 2 \mathrm{H}_{2} \mathrm{O}$ & $\mathrm{C}-7902$ & 31 & 2.1 \\
\hline $\mathrm{MgCl}_{2} 6 \mathrm{H}_{2} \mathrm{O}$ & $\mathrm{M}-2393$ & 8 & 0.4 \\
\hline
\end{tabular}

\section{Fertilization medium}

\begin{tabular}{llll}
\hline Reagent & Source & Amount & Final concentration \\
\hline TL - stock & $\mathrm{n} / \mathrm{a}$ & $10 \mathrm{ml}$ & $\mathrm{n} / \mathrm{a}$ \\
\hline BSA (fatty acid free) & Sigma A - 6003 & $60 \mathrm{mg}$ & $6 \mathrm{mg} / \mathrm{ml}$ \\
\hline Pyruvate stock & Sigma P - 5280 & $100 \mu \mathrm{l}$ & $0.2 \mathrm{mM}$ \\
\hline Gentamycin stock & Sigma G - 3632 & $5 \mu \mathrm{l}$ & $25 \mu \mathrm{g} / \mathrm{ml}$ \\
\hline
\end{tabular}




\section{APPENDIX 1 contd.}

CRlaa culture medium

\begin{tabular}{lllll}
\hline Reagent & Sigma Cat. No. & $\mathbf{m g} / \mathbf{1 0 m l}$ & $\mathbf{m g} / \mathbf{2 5 \mathrm { ml }}$ & Final concentration \\
\hline $\mathrm{NaCl}$ & $\mathrm{S}-5886$ & 67 & 167.5 & $114.7 \mathrm{mM}$ \\
\hline $\mathrm{KCl}$ & $\mathrm{P}-5405$ & 2.3 & 5.8 & $3.1 \mathrm{mM}$ \\
\hline $\mathrm{NaHCO}_{3}$ & $\mathrm{~S}-5761$ & 22 & 55 & $26.2 \mathrm{mM}$ \\
\hline $\mathrm{L}-$ glutamine & $\mathrm{G}-3126$ & 1.5 & 3.8 & $1.0 \mathrm{mM}$ \\
\hline Pyruvate & $\mathrm{P}-5280$ & 0.4 & 1.0 & $0.4 \mathrm{mM}$ \\
\hline $\mathrm{L}(+)$ - lactate & $\mathrm{L}-4388$ & 5.5 & 13.8 & $5.0 \mathrm{mM}$ \\
\hline Gentamycin stock & $\mathrm{G}-3632$ & $5 \mu \mathrm{l}$ & $12.5 \mu \mathrm{l}$ & $25 \mu \mathrm{g} / \mathrm{ml}$ \\
\hline BSA (fatty acid free) & $\mathrm{A}-6003$ & 30 & 75 & $3 \mathrm{mg} / \mathrm{ml}$ \\
\hline MEM amino acids & $\mathrm{M}-7145$ & $100 \mu \mathrm{l}$ & $250 \mu \mathrm{l}$ & \\
\hline BME amino acids & B - 6766 & $200 \mu \mathrm{l}$ & $500 \mu \mathrm{l}$ & \\
\hline
\end{tabular}

Solutions for slide making for controls

\section{Mountant}

1 part paraffin mixed with 3 parts vaseline and heated. Once well mixed, load into a $10 \mathrm{ml}$ syringe.

\section{Fixative solution}

1 part glacial acetic acid and 3 parts absolute ethanol

\section{Aceto-orcein stain}

$0.5 \mathrm{~g}$ orcein (Hopkin and Williams Ltd.) Mixed with $30 \mathrm{ml}$ double distilled water, heated and stirred overnight. Add $20 \mathrm{ml}$ glacial acetic acid and filter solution through a Whatman ( $7 \mathrm{~cm}$ diameter) filter. 


\section{APPENDIX 2}

Determination of sperm motility by assessing number of sperm moving versus number dead

\begin{tabular}{|c|c|}
\hline Percentage & Ratio \\
\hline $100 \%$ & infinity versus zero \\
\hline $99 \%$ & 99 versus one \\
\hline $95 \%$ & 19 versus one \\
\hline $90 \%$ & 9 versus one \\
\hline $85 \%$ & 7 versus one \\
\hline $80 \%$ & 4 versus one \\
\hline $75 \%$ & 3 versus one \\
\hline $70 \%$ & $21 / 2$ versus one \\
\hline $65 \%$ & 2 versus one \\
\hline $60 \%$ & $11 / 2$ versus one \\
\hline $55 \%$ & between ratios for $60 \%$ and $50 \%$ \\
\hline $50 \%$ & one versus one \\
\hline $45 \%$ & between ratios for $40 \%$ and $50 \%$ \\
\hline $40 \%$ & one versus $11 / 2$ \\
\hline $35 \%$ & one versus 2 \\
\hline $30 \%$ & one versus $21 / 2$ \\
\hline $25 \%$ & one versus 3 \\
\hline $20 \%$ & one versus 4 \\
\hline $15 \%$ & one versus 7 \\
\hline $10 \%$ & one versus 9 \\
\hline $5 \%$ & one versus 19 \\
\hline $1 \%$ & one versus 99 \\
\hline $0 \%$ & zero versus infinity \\
\hline
\end{tabular}

Taken from Nothling and Arndt (1996) 


\section{APPENDIX 2 contd.}

Abnormal morphology evaluation sheet for spermatozoa

\begin{tabular}{|c|c|}
\hline Date: & \\
\hline MAJOR DEFECTS & Total \\
\hline 1. Teratoid & \\
\hline 2. Knobbed Acrosomes & \\
\hline 3. Pyriform Heads & \\
\hline 4. Nuclear Vacuoles & \\
\hline 5. Folded Head & \\
\hline 6. Macrocephalic & \\
\hline 7. Microcephalic & \\
\hline 8. Abnormal Loose Head & \\
\hline 9. Double Forms & \\
\hline 10. Degenerative Heads & \\
\hline 11. Corkscrew Head & \\
\hline 12. Stump tail & \\
\hline 13. Midpiece Defects & \\
\hline 14. Dags & \\
\hline 15. Broken tails & \\
\hline 16. Proximal or Pseudo Droplet & \\
\hline MINOR DEFECTS & \\
\hline 17. Loose Normal Heads & \\
\hline 18. Degenerative/Loose Acrosomes & \\
\hline 19. Abaxial Implantation & \\
\hline 20. Curved Headpiece/Endpiece & \\
\hline 21. Distal Droplet & \\
\hline Number of major and minor defects (\%) & \\
\hline
\end{tabular}

